\title{
The Road Ahead to Real-Time Oil \& Gas Reservoir Management
}

\author{
Reid G Smith and Geoffrey C Maitland ${ }^{+}$ \\ Schlumberger Limited, 300 Schlumberger Drive, Sugar Land, TX, 77478, USA \\ + Schlumberger Cambridge Research, High Cross, Madingley Road, Cambridge CB2 0EL, UK
}

Transactions of the Institution of Chemical Engineers: Chemical Engineering Research and Design, Vol 76A, pp. 539-552, 1998. (Awarded the 1998

Hutchison medal by the Institution of Chemical Engineers.)

The aim of this paper is to provide a vision of how the processes and materials used to extract hydrocarbons from underground reservoirs might evolve over the next decade or so, in order to stimulate and provide signposts for the research and development which is needed to meet the industry's future needs. The target is to double the recovery of hydrocarbon in place from today's typical values of 30-40\%. This will require real-time reservoir management, for which the ability to simulate, monitor and control all the key processes that take place within the reservoir and production system is a fundamental requirement. A particular emphasis is placed on the role to be played by chemical and process engineering. Existing exploration and production practices are summarized and possible scenarios described for the way in which the enabling technology and engineering might evolve. This is done by presenting a series of technology roadmaps and cartoon future scenarios for four technology packages that together have the potential to enable a new era in productivity. Oil and gas wells can be likened to high pressure, high temperature tubular reactors, whose geometry and sophistication is becoming increasingly complex. It is envisaged that the oil reservoir of the future will evolve towards a subterranean factory of interconnecting drainholes, whose overall efficiency in producing saleable products will be determined by the way that its individual production units are deployed and coupled in the light of market needs. Linked to improved understanding of the regional geology, optimising the downhole factory productivity will enable the operators to reduce significantly their investment risks and substantially increase worldwide recovery rates.

Keywords: oilfield; reservoir management; process optimization and control; flow simulation; porous media; complex fluids; multiphase flow; sensors; smart materials 


\section{Introduction}

The aim of this review is somewhat different than those normally commissioned for this Journal. The topic is the science and engineering of hydrocarbon recovery processes and, whilst providing a summary of existing practices, the main aim is to provide a vision of how these practices might evolve over the next decade or so. It is hoped that this will provide a stimulus for both academic research and enhanced collaboration between universities, the service sector and oil companies to enable such a vision to be achieved and even surpassed.

The scenario on which this picture of the future is based assumes that, as for the past decade, hydrocarbon prices will remain relatively low for some time into the future. The consequence of this is that, with new reserves being discovered in increasingly difficult to exploit locations (deep water, cold climates etc.), the only way for oil and gas extraction to remain economically viable is to maintain and reduce the lifting costs by the development of increasingly cost-effective new technology. After a decade when oil supply has significantly exceeded demand, these curves are now converging, and at some stage will undoubtedly cross. Estimates of when this will occur vary (3-10 years) along with those for the total recoverable reserves in place (850 - $2000 \mathrm{Bbbl})[1$ $\mathrm{bbl}=159 \mathrm{l}]$ and when global production of conventional oil will start to decline (2010-2030) ${ }^{1}$. However, the bottom line is that recovery cost and efficiency will continue to be strong drivers throughout this evolution. Consumption up to the end of 1997 was $900 \mathrm{Bbbl}$ and the most optimistic of models predicts that consumption will exceed reserves in place by 2012 .

In this context, the major drivers for oilfield technology fall into five main categories:

- Optimising the costs and efficiency of well construction

- Introducing surface to reservoir drainholes in the most cost-effective manner

- Maximizing well productivity

- Optimising the connectivity of individual wells to the producing reservoir

- Managing reservoirs to optimize the overall recovery

- Optimising the placement/treatment of wells and fluid drainage patterns

- Ensuring environmental compliance and best practices

- Adopting a pro-active approach to minimising environmental impact

- Being able to operate in increasingly extreme conditions

- Coping with the extremes of water depth, climate, reservoir depth, location access etc that are characteristic of almost all new reserves discoveries

A simply stated but challenging goal that emerges from these drivers is to increase recovery by a factor of two - from the current typical levels of 30-40\% towards $60-80 \%$ or beyond. We take the view that to reach this target will require Real-time Reservoir Management. [Reservoir Management has been defined by Al-Hussainy and Humphreys ${ }^{2}$ as 'the marshaling of all appropriate business, technical and operating resources to exploit a reservoir optimally from discovery to abandonment...'.] To achieve this, the ability to simulate, monitor and control in real time all the key processes that occur within the reservoir and production system is a fundamental requirement. These technologies are at the heart of Chemical and Process Engineering; we aim to demonstrate that whilst mechanical, electrical and electronic engineering advances will continue to be key to meeting the technical challenges that lie ahead in extracting hydrocarbons from the earth, the techniques of process automation, optimization and control that are commonplace in the chemical and process industries have a major role to play in the evolution, or even revolution, of the industry. In many ways, an oil well is nothing more than a high temperature, high pressure (HTHP) tubular reactor, in both its construction and production phases, and a reservoir is an 
underground factory whose overall efficiency in producing saleable products is determined by the way that its individual production units are deployed and coupled in the light of market needs. Linked to improved understanding of regional geology, optimising the downhole factory productivity will enable the operators to reduce significantly their investment risks and substantially increase worldwide recovery rates.

It is worth pointing out that in setting the goal of increasing reservoir recoveries to $80 \%$, we are not entering the realms of enhanced or tertiary oil recovery (EOR). This regime is concerned with extracting oil that is trapped within the fine capillary structure of a porous reservoir, and requires technology that addresses the additional capillary pressures that arise at the pore level (microns) in such circumstances ${ }^{3}$. The increase from $40 \%$ to $80 \%$ recovery can by and large be addressed by improving the global sweep, or conformance control, of the reservoir by recognising that it is highly heterogeneous at the $\mathrm{cm}$ scale or above, both through permeability contrasts and the existence of natural fractures and faults. It is this regime that is the target of what is usually termed today Improved Oil Recovery or $\mathrm{IOR}^{4}$, and it is within this context that this paper is written.

The approach we take is to examine four areas of oilfield technology that are on the critical path towards achieving this goal. For each we describe a 'Technology Roadmap' - the way ahead which charts the possible evolution of the science and technology that needs to be developed and integrated to reach this new era in reservoir productivity. The roadmap method has been popularized by Motorola ${ }^{5}$ as an orderly process for developing a picture of future technology, together with a projection of its evolution over time. It was originally intended as a practical tool to encourage business managers to give proper attention to their technological future. It also provides a means of communicating to engineers and marketing personnel which technologies will be requiring development and application for future products.

The process starts by stating a clear overall target, based on product market, competitive or technology trends. For the upstream exploration and development sector of the industry, we are suggesting doubling economic hydrocarbon recovery. Armed with such a target, developing the roadmap is an iterative brainstorming process, often involving people from a variety of functions (e.g. R\&D, manufacturing, marketing, business). The fact that roadmap time frames tend to extend well beyond conventional business and product planning horizons adds to the challenge. Another benefit of the process is that it forces the participants to be explicit about their assumptions - to make clear the problems that must be solved to reach the target, the order in which they will be solved, and the expected interim results.

The process has been adopted by the US semiconductor industry overall, where it has been used to provide a common vision - a framework to guide R\&D for all sectors of the US semiconductor technology base - industry, universities, and government organizations ${ }^{6}$. The overall target was established by extending historic trends for dynamic random access memory (DRAM) bit count by a factor of four every three years until 2010; this implies $64 \mathrm{~Gb} / \mathrm{chip}$ in 2010. From that follow the requirements for supporting technology to enable such devices to be designed, manufactured, and tested.

In describing how current approaches might evolve or be replaced, we show how each of these supporting technology packages might change the nature of the surface and downhole hardware employed, and the way the reservoir is managed, through a series of cartoons. These demonstrate how implementing a process/systems engineering approach to exploiting the reservoir can 
respond to the various drivers and constraints mentioned earlier. We should emphasize that the roadmaps and cartoons do not represent the R\&D strategy of Schlumberger. Meeting the challenges described here ${ }^{7}$ requires an overall industry effort - building on the work of operators, service companies, academics, SME's, and government.

\section{The Reservoir Management Process}

For many years, the dream of the oil company operators has been to integrate the data, interpretations, models, simulations, and effects of development and production decisions in such a way as to optimally deplete the reservoir according to a business model and economic constraints. The basic steps are shown in Figure 1.

\section{Reservoir Management Process}

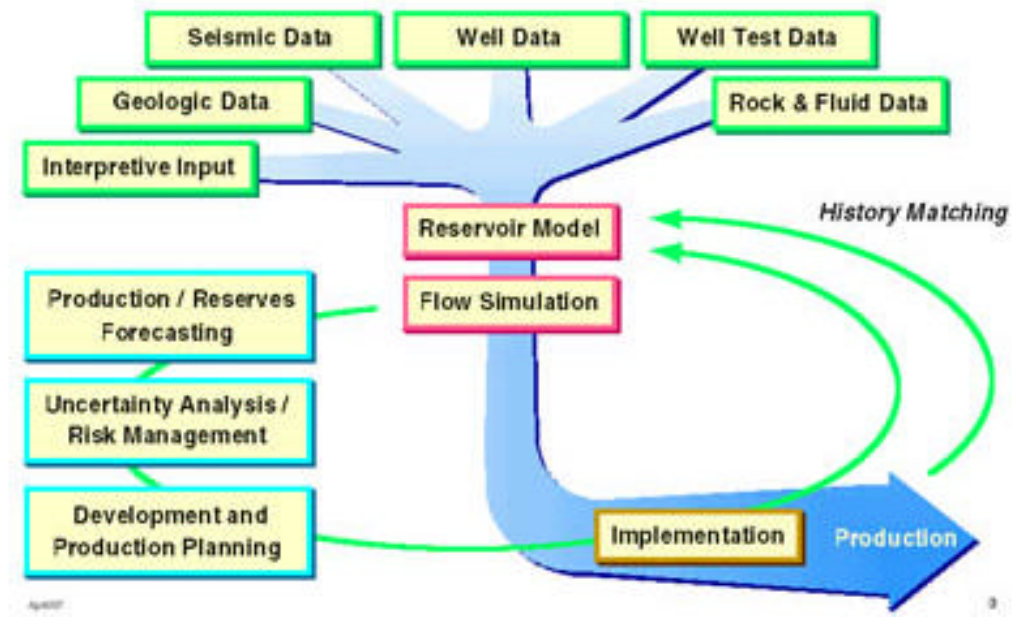

Figure 1. Key inputs and basic steps of the overall Reservoir Management Process.

A central step in reservoir management is development of a reservoir model that can be used in mapping the distribution of fluids, identifying unswept reservoir volumes and developing production strategies, including placement of infill wells, design of injection and production programs (such as extended well testing), and targeting of

horizontal and multilateral (multiple wells from the same primary wellbore, possibly with further branches and sub-branches - see section 4, Well Construction) wells. The model must capture reservoir geometry, internal architecture, rock properties and their variability, fluid content and distribution, fluid properties and producibility. Key elements of the flow simulation include the fluid mechanics of multiphase fluids in complex porous and fractured media, the thermophysical properties of hydrocarbon fluid/aqueous salt solution mixtures and their variation with temperature/pressure and their thermodynamic phase behavior under reservoir and production conditions. The overall objective of building the model is reduced reservoir uncertainty in a broad sense, from prospect appraisal to production extension. This is a key to exploration risk reduction and to optimum reservoir management.

Not shown in the figure, but underlying all elements of the process, is the Data Management system responsible for all data involved in reservoir management. Efficient data management and software integration are of prime importance throughout. They often limit the practicality of iterative, detailed reservoir model development and 'what if' scenario planning.

In what follows we touch on many of the boxes shown in the Figure, including the extremely important field 'Implementation' - taking action based on the data, modeling, and simulation. Given this is the reservoir management process of today, what technology advances could result in substantial improvement? We discuss this under four headings, key technology highways on our route to doubling recovery: 
- Reservoir modeling

- Well construction

- Well productivity optimization

- Reservoir management

\section{Reservoir Modeling: Towards the Shared Earth Model}

In obtaining suitable models of the reservoir, the focus is technology aimed at risk reduction by acquiring new data, enabling fuller use of acquired data and improving reservoir modeling and simulation. The roadmap for this domain is shown in Figure 2.

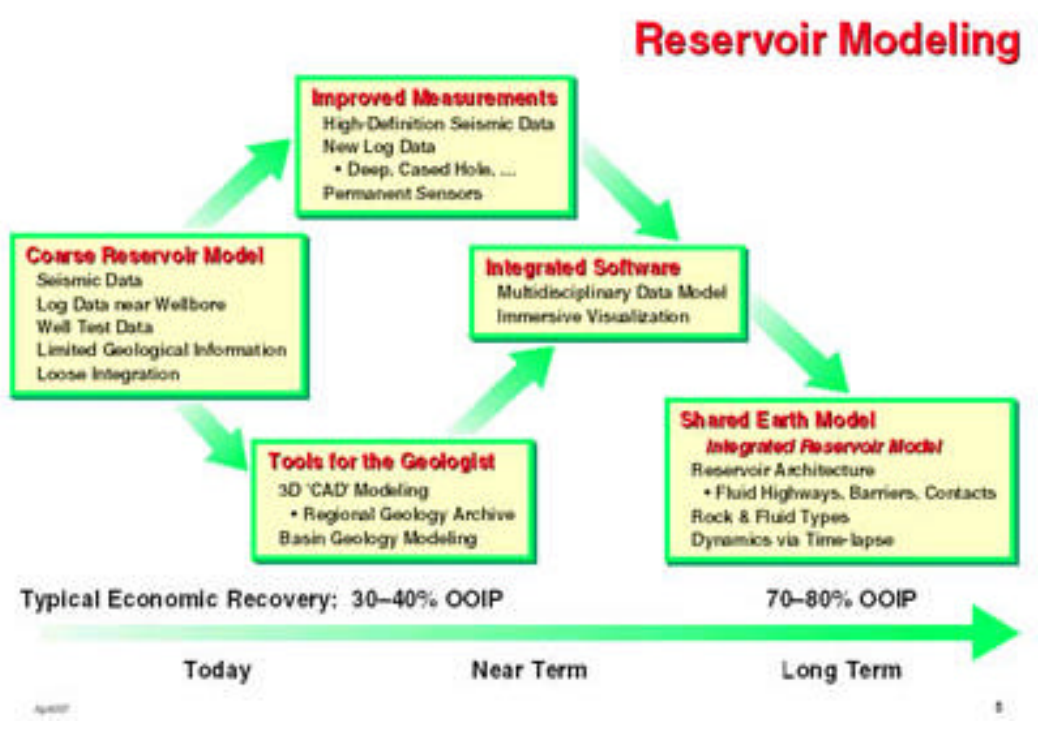

Figure 2. Reservoir modeling roadmap; the time scale proceeds from left to right and covers, say, a ten year period.

As for each roadmap, Figure 2 has a time axis proceeding from left to right. On the left-hand side, labelled Today, we show the current state of the art in the industry. On the right-hand side, labelled Long Term, we indicate the possible state of the technology and practice over, perhaps, a 10 year period. Also shown are some Near Term

milestones. The arrows indicate evolution of the individual elements. Along the time axis is shown the overall target - doubling economically viable hydrocarbon recovery. If today the goal is $30-40 \%$, not unrealistic for North Sea reservoirs, then the long-term goal is 60-80\% recovery. In other reservoirs, the economically viable numbers may be much lower, but the goal of doubling recovery remains.

The roadmaps emphasize the broad technologies and engineering issues that are the key stepping stones to progress. They do not show all the detail, such as technical options, decision points, critical success factors, required core competencies etc. that are needed to define a specific plan of action. They are the framework within which the more detailed technologies we describe, and those which the community has yet to develop, fit together and act as a guide to the capabilities and timing required of these new technologies.

\subsection{Existing Technology - Coarse Reservoir Model}

In today's oilfields, the reliability of reservoir simulation and production forecasting is often limited by the accuracy of the reservoir model. Many failures in pilot and field-wide IOR projects can be attributed to the poor quality of the reservoir model used to simulate the process; the decision to go ahead with the project had been based on overly optimistic forecasts of reservoir performance, which mainly resulted from an inadequate description of reservoir heterogeneity. We have what is termed a coarse reservoir model.

With present industry techniques, reservoir models are typically built by first delineating major 
horizons and faults from surface seismic data (see Figure 3). Most would argue that 3D seismic imaging has had a major effect on the upstream business in recent years ${ }^{8}$. On the other hand, while steady progress has been made to reduce acquisition costs, much remains to be done, especially for land and shallow water seismics

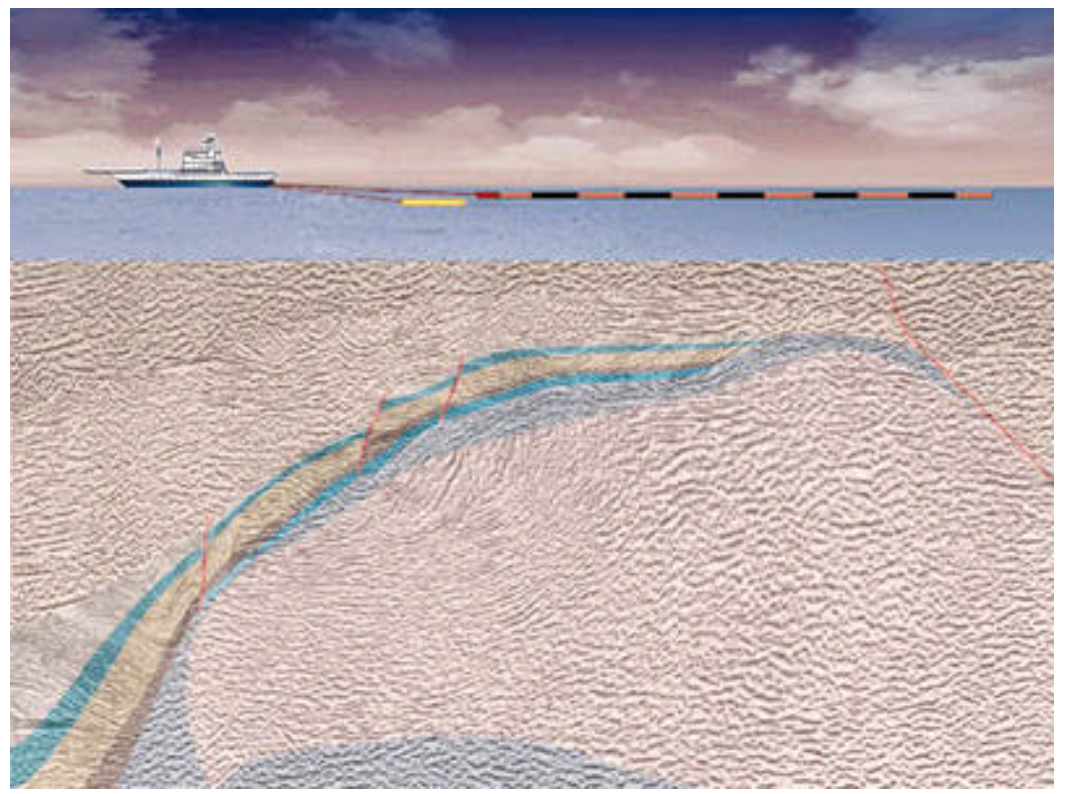

Figure 3. Marine seismic surveying. The vessel tows arrays of air gun sources and hydrophone detectors at a speed of about 5 knots $(9.3 \mathrm{~km} / \mathrm{hr})$. The high amplitude sound waves reflect off the underlying rocks and are detected by the hydrophones to give sequences of two-way travel times. The huge datasets are sent to specialized processing centres where they are used to create an image of the subsurface geological structure.

\section{Reservoir geometry and} properties are then defined at a resolution much finer than seismic through use of well-log data see Figure 4. Electrical, acoustic, gamma ray and other radiation probes ${ }^{9}$ are being deployed with increasing resolution, acquisition efficiency, depth of investigation and reliability to map out the rock and fluid features away from a drilled wellbore. These data are already routinely transmitted by satellite to remote offices in real-time. Well test data can help define reservoir characteristics further from the wellbore. In recent years, there has been much effort devoted to extended well testing/early production systems. An example is the BP Machar field in the UK North Sea.

Figure 4. Illustration of how the lithology, geometry, properties and pore fluids are defined with much higher resolution than the coarse seismic detection of the major horizons and faults, by the use of electrical, acoustic, gamma-ray and other radiation probes on wireline tools. These tools are placed in the wellbore and moved axially and azimuthally to build up a 3D image of the near-wellbore region.

Geology is only handled in an ad hoc way (e.g. by specifying a

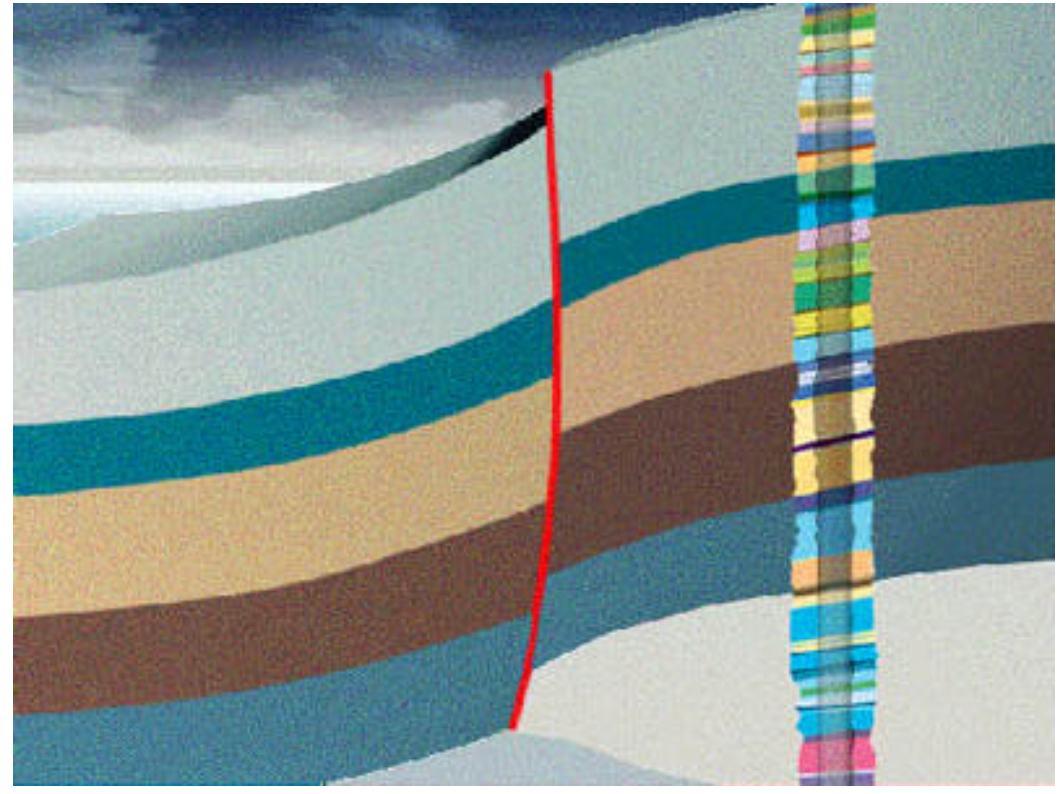
statistical correlation distance parameter) given the limited geological information available and there is only loose integration of the various data inputs to the model. Many software packages are available, at different scales of integration ${ }^{10}$. 


\section{Near Term}

\section{Improved Measurements}

In the near term, we can expect improvements in existing measurements, as well as introduction of new measurements. A number of approaches are being explored for improving the definition of seismic data. Some efforts are aimed at improving resolution from the current $20-100 \mathrm{~m}$. Others are aimed at elucidation of fluid contacts, as well as rock and fluid properties. In addition, there is much activity surrounding 4D, or time-lapse, data. One recent example of this is the BP-Shell Foinaven field, West of Shetlands, where periodic seismic surveys combine data from conventional towed streamers and a seismic monitoring system, consisting of a sea-bed mounted array of permanent sensors. In Foinaven, where each well represents a large investment in drilling, completion, and subsea infrastructure, 4D seismic may permit the operator to reduce the number of wells necessary to access the oil, resulting in a substantial reduction in development costs.

Another example of the use of the technique is by Statoil in the N Sea Gullfaks field ${ }^{11}$. In Figure 5 a comparison of seismic images acquired in 1985 (left) and 1995 (right) shows the reservoir changes that have occurred as this field has been produced. Overall, oil has been replaced by water in the lower, western sections of each fault block. This indicates a relatively smooth sweep. In some areas, however, such as in the northern part of the middle fault block, oil and gas appear to be in a separate compartment that has not been tapped. An assessment of actual drainage patterns is helping Statoil reservoir engineers optimize the management of reserves.

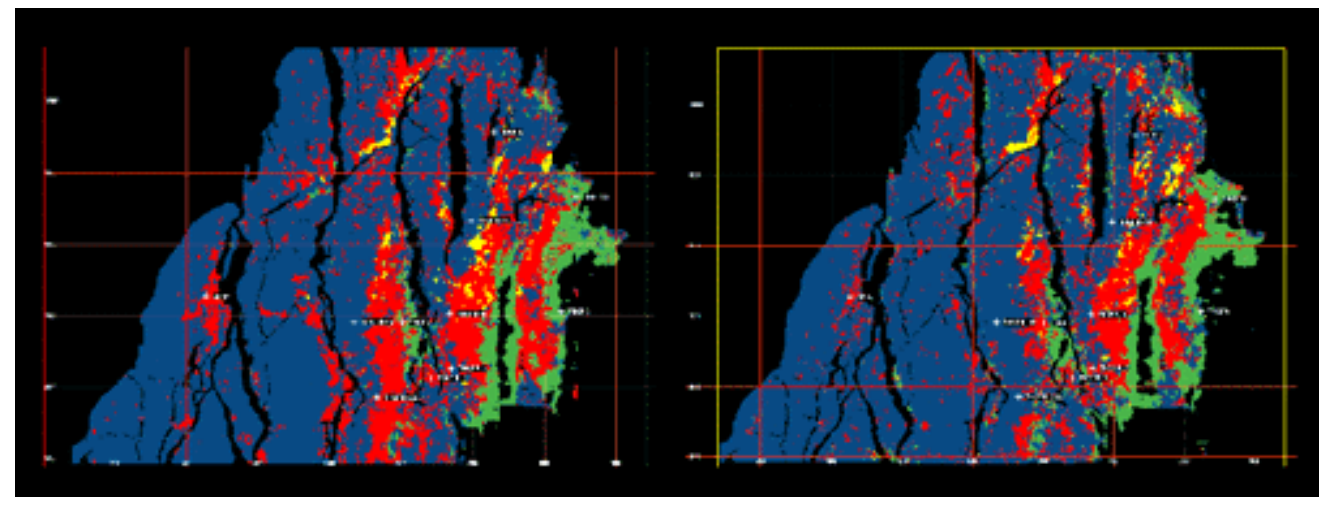

Figure 5. 4D time-lapse seismic reservoir monitoring: a comparison of seismic images showing fluid distributions before and after production from the Norwegian North Sea Gullfaks field ${ }^{10}$. ten years of oil Oil $=$ red, gas $=$ yellow, water $=$ blue, non-reservoir $=$ green .

In addition, we can expect improved measurements (e.g. NMR, optical logging, fluorescence) and deep measurements, for both cased-hole and open-hole applications. For instance, NMR ${ }^{12}$ is used to deduce permeability, free-fluid porosity, the porosity irrespective of the lithology, and a new petrophysical parameter - pore size distribution. These parameters will help interpreters locate by-passed oil, predict overall productivity and make completion decisions. We can also expect new measurements, perhaps involving chemical/biochemical sensors and nanotechnology, aimed at improved characterization of the local chemical nature of the reservoir and its fluids.

An area which complements attempts to improve the resolution of seismics data where near-term developments are feasible is by extending log measurements away from the borehole, in freshly drilled wellbores and in those that have been cased with a steel lining. In addition, as more wells 
are drilled with multiple laterals, cross-well measurements are likely to make a comeback in the guise of cross-lateral measurements (e.g. electromagnetic, acoustic). New permanent sensors will be installed within wells for both production monitoring and formation evaluation.

\section{Tools for the Geologist}

In parallel, new tools will be developed for the Geologist. These will include new measurements and/or applications (e.g. paleo-magnetism, geochemistry, age, depositional environment, sequence stratigraphy). Today, building a reservoir model is a time-consuming and difficult process. However, we can see the beginnings of CAD-like systems to assist geologists in building, and refining models. These systems include geoscience extensions to the traditional geometric and topological representations of mechanical CAD.

Advances in IT, specifically 3D graphics and web browsers, are leveraged to provide the geologist with a new tool kit to sit on top of an integrated data management system ${ }^{13}$. The geologist is able to see all of the oil field data (thin sections, cores, borehole images, seismic amplitudes, etc.) at their true scale and in their correct spatial context. By using an online archive of geological knowledge, he is able to make a 3D interpretation of the geology of the oil field and to view this interpretation in the context of the data. The interpretation may then be exported to support fluid flow simulation, well planning, etc.

New tools for basin geology modeling are also of interest. They perform mathematical simulation of physical and chemical geological processes at the scale of the sedimentary basin. The modeling entails the prediction of the deposition and burial history of rocks, their temperature histories, the location, amounts, type, and timing of hydrocarbons generated and the location, amounts, type, and timing of accumulations and losses. Questions that may be answered by basin simulations include: when did structures fill and with what, how likely is it that spillage has taken place, what are the most crucial parameters to these assessments, and is it possible to determine these events better? In the near term, we can expect improvements to be made to the current 1D modeling capability, and to see these systems integrated with the CAD-like and other modeling systems.

\section{Integrated Software}

There are in fact two integration problems that need addressing. First, how to design software frameworks so that future applications can be folded into an existing ensemble in a seamless and straightforward manner. Second, how to integrate the measured and interpreted geoscience data from the point of view of the reservoir physics and chemistry, across a great variety of scales.

The former, software problem is likely to be solved before the geoscience problem since integration of diverse packages is a central problem facing the entire software industry, rather than a problem unique to the oil industry. However, there is a piece the oil industry must address by itself - the design and evolution of a standard Multidisciplinary Data Model, i.e. one which is able to integrate data as diverse as seismic, real-time drilling, and production data. Immersive visualization, or virtual reality interaction, is another technique that is likely to prove a powerful aid in enabling the models to be used by generalists. The ability of reservoir managers to roam through the producing and evolving reservoir, taking real-time production decisions, is an enticing prospect. 


\section{Long Term - Integrated Reservoir Model}

The end goal is development of the technology necessary to enable use of a single, integrated reservoir model, commonly called the 'Shared Earth Model.' It is 'the one model for all data' (geometric, geological, geophysical, petrophysical, geochemical, reservoir, fluid flow, fluid physics...). It must be both verifiable and predictive and be capable of capturing the reservoir architecture, the fluid highways, barriers, and contacts, together with rock and fluid types and properties.

Time-lapse measurements will include 4D seismic data, but will include a variety of other data as well. For instance more proactive, interventional characterization procedures (such as advanced, smart tracer techniques) will be developed to complement methods which simply monitor the naturally evolving reservoir. Eventually 5D data could become the norm, with the dimensionality increased to include a dimension spanning different data types. A central focus of current research is methods for better constraining 4D reservoir modeling by more complete assimilation of measurements across many scales, consideration of realistic geological discontinuities and early incorporation of dynamic data. The objective is twofold:

1. to make better use of all available data and

2. to significantly decrease the time it takes to obtain a fluid flow simulation model that fits the data and can be used for prediction.

Progress here is vital to enabling practical reservoir models to be built and updated in an iterative manner to aid production decisions. Models obtained by direct inversion of such data combinations, rather then by fitting and extrapolation, are likely to prove a key element.

Alongside the improved models of reservoir structure and permeability maps, and the provision of techniques to monitor fluid movements within the reservoir for both model calibration and validation purposes, there are great challenges for the fluid mechanicians. The techniques for modeling the flow of multiphase fluids in heterogeneous porous media must keep pace with the level of detail and complexity with which the matrix permeability distribution will be capable of being specified - or plausible geostatistical stochastic realizations developed. Today, a variety of upscaling techniques are used to coarsen permeability data, specified or constructed with high spatial resolution, to the lower resolution that present day flow simulators can handle. While single phase flow permeability can be upscaled with some confidence, methodology for upscaling a two-phase flow description is still a topic of active research.

The speed, accuracy and spatial resolution of the simulation will need to meet the demands of real-time applications and of using 4D data from a range of sources to update and refine the integrated model. There will therefore be much scope for methodology development. Today, streamline-based flow simulation methods are advocated as a means to speed up simulations, by effectively adapting the computational grid to the permeability field and flow solution. It is clear that there are many further advances to be made by exploiting the possiblitieis of solutionadaptive geometry, physics and discretization. Improved models for fluid thermophysical properties at reservoir conditions will also be needed; for example, as greater chemical detail is sensed and simulated, we must re-think the degree to which species can be lumped together and treated as a single effective component.

Figure 6 is a cartoon illustrating the impact of reservoir modeling in the era of the Shared Earth Model. We see an engineer in coveralls virtually immersed in the data - the virtual reservoir. 
Another geoscience specialist colleague or client is sitting in an office distant from the reservoir, also immersed in the data, relayed by satellite. The analysts work with the parts of the reservoir which have already been illuminated. This information is relayed and presented as 'immersive visualization' in the office environment. Ghostly manifestations of the illuminated parts of the reservoir float in the remote office and surround the analyst. Over time, the detail will increase, as will the level of illumination and coloring/texturing representing reservoir parameters.

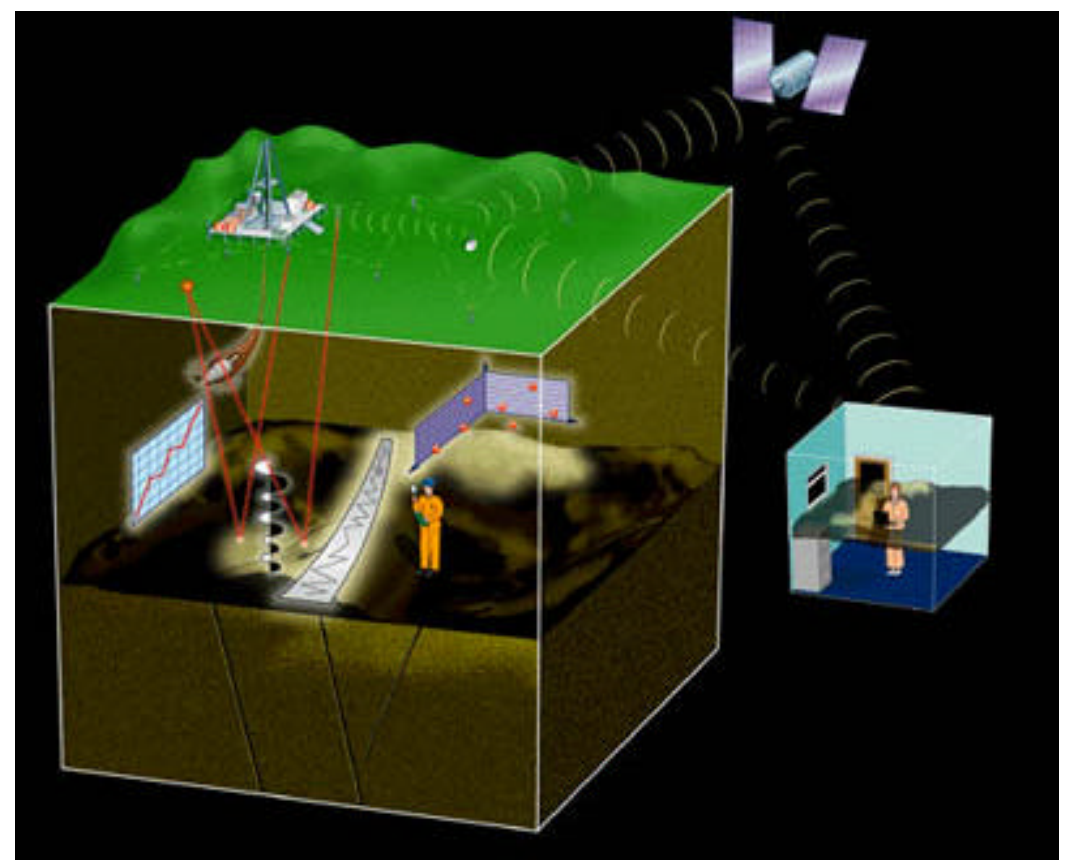

Figure 6. Cartoon projection of reservoir operations in the era of the Shared Earth Model.

A large rig in the corner has drilled (unsuccessfully) a part of the earth 'cube.' The track of the well has illuminated that part of the cube in a pale, cylindrical cylinder representing Logging/Measurements-whileDrilling (LWD/MWD) measurements. Above the reservoir top are icons representing different sorts of 'shared earth model' data - a 2D graph for petrophysical modeling, a couple of ray paths and a trace for seismic

modeling and acquisition, a 3-D graph for classification system, a strip of well log, etc. Each icon emits a 'glow' which illuminates the reservoir. The log illuminates a strip where the well would have passed, the seismic rays illuminate concentrated spots at the point of reflection and a 'curtain' of light where they pass vertically, and the graphs cast a wide but pale light.

There are clearly areas of dark 'gloom' around the cube where no light has yet been thrown. The illuminated parts of the reservoir are reproduced in the office. A randomly organized set of surface sensors communicate to a central point. These could be permanent seismic-while-drilling geophones or any other wireless sensors.

\section{Well Construction: Towards reservoir plumbing - optimal access to the undamaged reservoir}

In addition to these important data and simulation issues, there are two major 'field implementation' issues. The first of these is how we construct the well; the roadmap in Figure 7 illustrates an anticipated evolution of the Well Construction Process. 


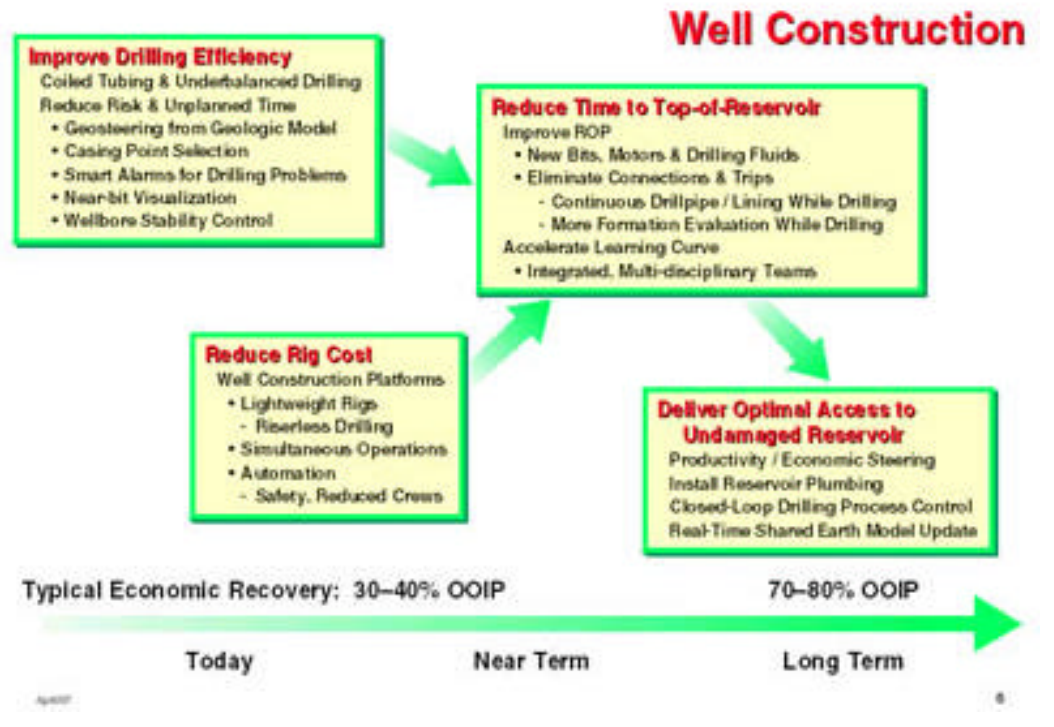

Figure 7. Roadmap illustrating the possible evolution of the Well Construction Process.

\section{Existing Technology - Improving Drilling Efficiency}

A major advance over the past 10-15 years has been the development of flexible advanced drilling technologies, including steerable downhole motors, MWD and LWD, which have enabled directional drilling to become routine ${ }^{14}$. Vertical wells (of which typically 25 would be required to produce, say, 50,000 bbl of oil per day, along with perhaps $15,000 \mathrm{bbl}$ of unwanted water) have given way to deviated and horizontal extended-reach wells within the reservoir - see Figure 8 - (whose productivity is typically about five times that of a vertical well due to the increased production contact area with the reservoir; only 5 would be required to produce the same 50,000 bopd, along with only, say, 5,000 bbl of water).

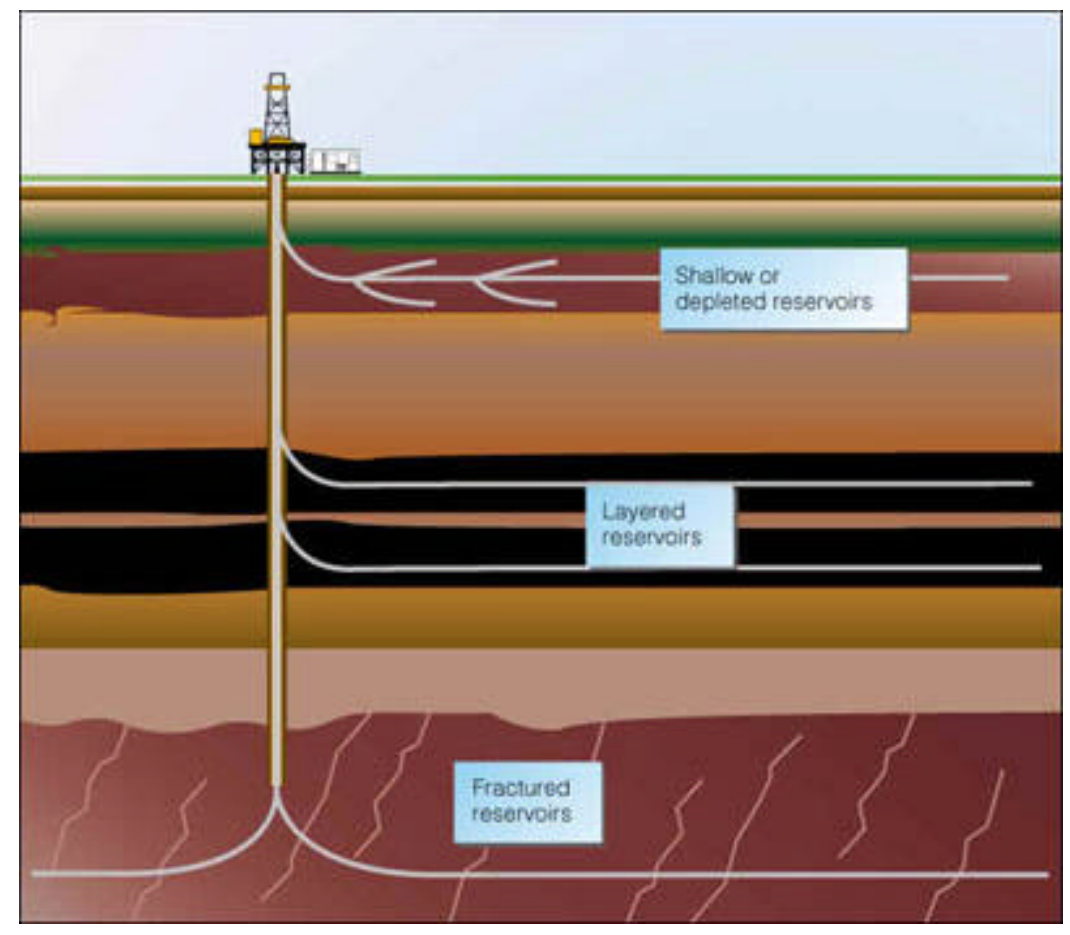

Figure 8. Multilateral drilling for improving productivity. In depleted zones, a network of 'fishbone' laterals increases the length of wellbore contact with the reservoir (top lateral), which also reduces adverse pressure drawdown effects. Several isolated layers can also be tapped from the same wellbore (middle laterals). In a fractured reservoir, dual laterals intersect twice as many fractures (bottom laterals).

Figure 9 shows the state of the art for extended-reach drilling (ERD) today. This shows the envelope, in terms of true vertical depth vs. horizontal departure, of what can be considered as 'standard' vs 'advanced' technology. We can see that some of the most challenging wells have been drilled in the UK; in 1997, BP drilled a then world- 
record $10.5 \mathrm{~km}$ extended-reach well from their Wytch Farm facility in Dorset out underneath Poole harbor, combining high productivity with low (offshore) environmental impact ${ }^{15}$.

Figure 9. Industry comparison of extended-reach wells. What was once considered the envelope of extended-reach drilling now merely indicates the difference between standard and advanced

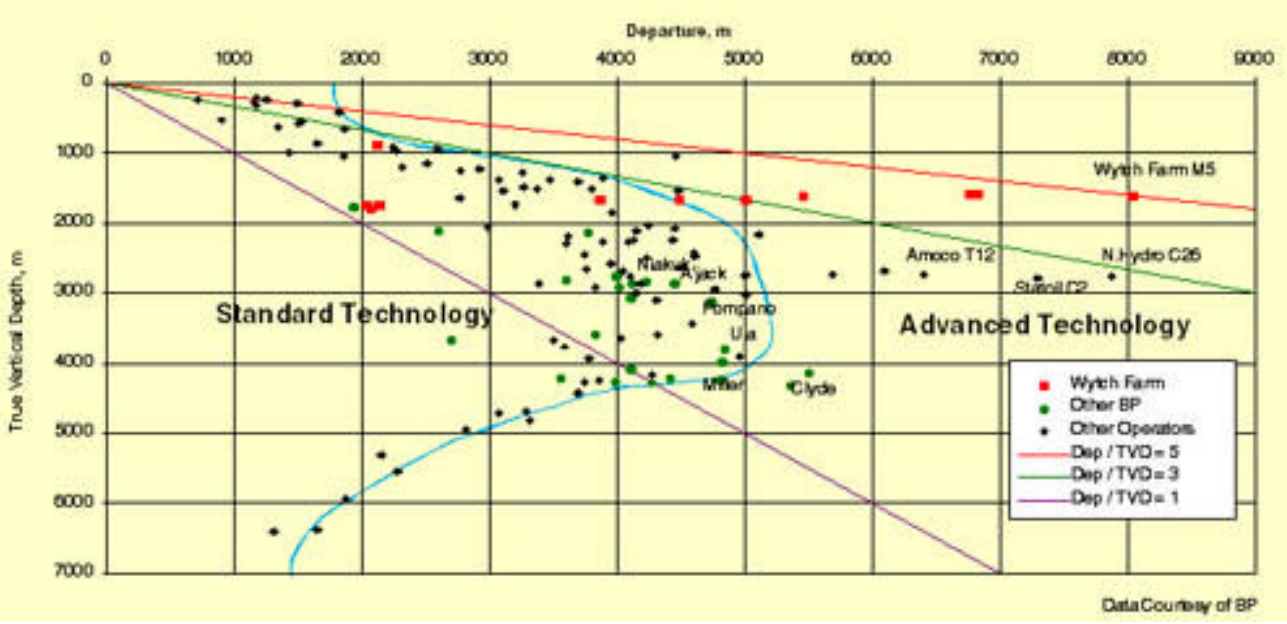
technology. That envelope continuously enlarges as companies push technology to the limit.

Today, the main goal is to improve drilling efficiency, assuming the reservoir model indicates correctly where we should drill. Another advance has been the use of coiled tubing ${ }^{16}$ (steel hosepipe, typically 4-6 cm in diameter which can be reeled down a well from a truck, removing the need for a full (expensive) drilling rig). This is used both for drilling new wells, and so-called reentry drilling ${ }^{17}$ whereby old, unproductive wells can be given a new lease of life by drilling sidetracks into pockets of the reservoir revealed as oil/gas-bearing by improved reservoir models and characterization. Underbalanced drilling ${ }^{18}$ is another way in which the drilling process is being modified to take into account the overall target - enhanced productivity. By changing from the traditional overbalanced scenario, whereby the wellbore pressure exerted by the drilling fluid exceeds the rock pore fluid pressure in order to avoid premature production of fluids (and possible blowouts), to controlled underbalanced conditions (with a 'shut-in' well) potentially prevents the invasion of damaging solids and chemically-incompatible fluids from the drilling fluid in the wellbore into the reservoir, avoiding so-called 'formation damage' and maintaining reservoir productivity at its incipient level. Such technology, whilst beneficial in principle, is not straightforward to apply in practice, requiring highly accurate pressure monitoring and control in both the reservoir and the wellbore, and is an area where process enhancements will undoubtedly bring benefits in the near to mid-term.

All these technologies are being applied regularly in some parts of the world to improve productivity via infill drilling and reduction in reservoir formation damage by the drilling fluids used to create the well. For example, it has been reported recently ${ }^{19}$ that Saga and Statoil plan to employ Coiled Tubing Drilling (CTD) in the Snorre and Gullfaks fields. Saga believes that by drilling multilateral horizontal wells it may be able to recover an additional $7.6 \mathrm{~m} \mathrm{bbl}$ of oil if successful. Likewise Shell have reported significant production enhancements by the use of horizontal drilling, percussion drilling, CTD and underbalanced drilling in Oman ${ }^{20}$.

Much of the cost of constructing a well lies in the downtime that arises from drilling problems, such as wellbore instabilities and drillstrings or logging tools becoming stuck in the hole. So much effort has and is going into ensuring reduced risk and unplanned time by improved, realtime decision-making aids that anticipate and diagnose problems, and appropriate corrective 
action, before they become critical - these take the form of both planning aids and so-called smart alarms.

For example, effective geosteering of horizontal wells can be aided by 3D geological models which help locate wells by avoiding faults and tapping high porosity zones. Figure 10 depicts Seismic While Drilling ${ }^{21}$ - imaging, using the drill bit as a seismic source, with geophones on the surface or sea bottom offshore. As the drill bit approaches an overpressured zone, which represents a potential gas kick or blowout hazard, the driller can see what is happening on the VSP (vertical seismic profile) image. The technique enables more accurate placement of the drill bit on the original surface seismic image. Several operators in the Far East have used the technique to save a steel casing string, and thus effect a substantial cost saving.

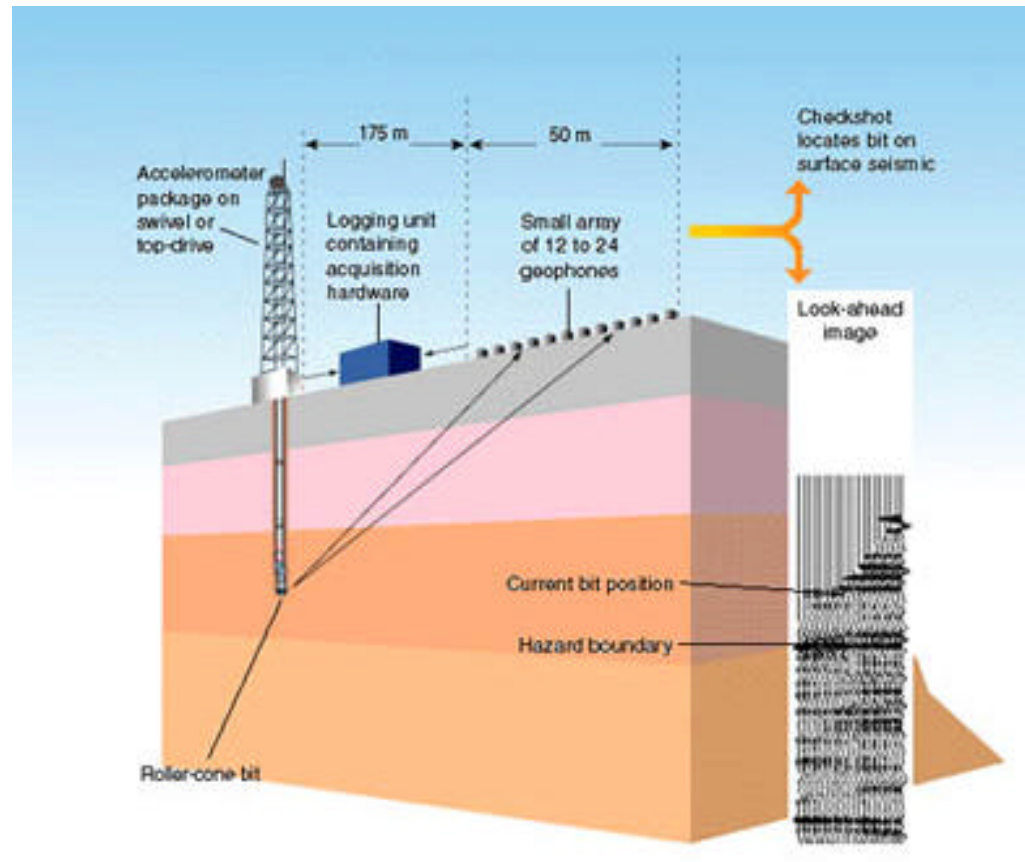

features like overpressurized gas pockets or the target depth.
Figure 10. Seismic While Drilling. The drill bit is used as a seismic source; acoustic energy travels upwards to receivers, up the drillstring (for calibration) and downward to reflect off layers ahead of the bit. The accelerometer and geophone signals are processed to extract relative travel time between the drillstring and formation paths. These whiledrilling time depth data can be used to locate the drill bit on the surface seismic images and produce a look-ahead image, an updated version of the original image with increasingly accurate depth locations for key

We are beginning to see 3D visualization being used to understand what is happening in the vicinity of the drill bit. In the future, we can expect new forms of visualization and virtual reality, coupled with new measurements, to permit the driller to understand what is ahead of, around, and behind the bit - the latter capability to identify incipient wellbore stability problems. Tomorrow's driller will be able to draw upon remote experts, also immersed in the data, in case help is required.

Figure 11 shows fracture orientation and aperture visualized with an ultrasonic imaging tool. Breakouts (stress-related damage in the plane of least horizontal stress) are seen on opposite sides of the borehole. There has been much written over the past years on the subject of wellbore stability $^{22}$ and some operators have made substantial progress in combatting the problem (e.g. the highly faulted and fractured Cusiana field in Colombia). Unfortunately, today this work is of most use in guiding drilling strategies on the next well to be drilled in an area, rather than for real-time guidance. However, research shows promise in real-time problem identification from real-time wellsite data, diagnosis of root causes, and suggestions for remedial actions. Over time, we expect to see improved measurements and understanding of the underlying mechanical and chemomechanical mechanisms ${ }^{23}$ result in closed-loop approaches. 
Figure 11. Wellbore drilling-related damage: breakouts (stress-related damage in the plane of least horizontal stress) are seen on opposite sides of the borehole. The fracture orientation and aperture are revealed by an ultrasonic borehole imaging tool.

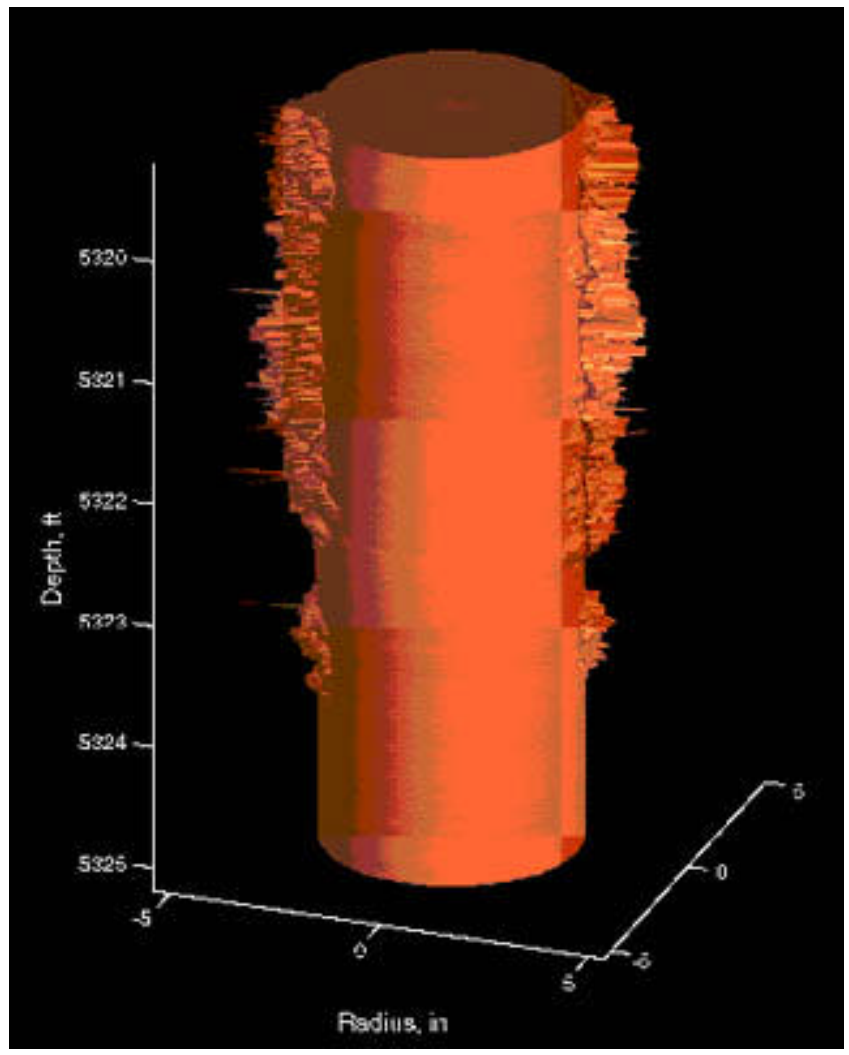

\section{Near - Term: Reduce Rig Cost}

In the near term, there are efforts ongoing in the industry aimed at reducing the cost of drilling rigs. The 'standard' well construction platform of tomorrow will consider the overall process, including directional drilling, wireline logging, the subsequent completion phase, etc. It will provide increased levels of integration, including physical space and networks.

Eliminating the marine riser ${ }^{24}$, the heavy fluid return pipe joining the seabed to the sea-level platform, is one way to reduce the necessary deck load capacity, and therefore the weight, of a well construction platform. Conoco and Hydril are exploring a riserless drilling concept which employs a $3000 \mathrm{ft}$ flexible lightweight umbilical for mud returns, and choke/kill well control safety operations. Elimination of marine risers is seen as an issue that will take on increasing importance as drilling operations move to ever deeper water in the future. Wells in the Gulf of Mexico are currently being drilled in $1000 \mathrm{~m}$ of water; drill-ships and platforms to drill in even greater depths $(>2500 \mathrm{~m})$ are planned for the year 2000.

Simultaneous operations are another way to improve efficiency and lower cost. For example, Shell has recently reported ${ }^{25}$ that Coiled Tubing Drilling was used in the North Sea to sidetrack an existing well through the completion, while the rig was drilling a conventional sidetrack. A related approach to improving rig efficiency for workover operations is to use multipurpose service vessels which reduce logistical complexity, improve operational flexibility and efficiency, and decrease time spent waiting on weather. Using the same equipment (pumps, mixers etc.) for several types of operation or fluid (e.g. drilling, cementing) is also helping to reduce rig costs and size.

Automation offers a number of potential advantages, including improved performance, improved 
safety by moving people out of a dangerous environment, and reduced cost by reducing the necessary crew. A BP investigation ${ }^{26}$ into cost drivers for well construction in the Ula Gyda Asset identified offshore personnel as the biggest single cost driver, accounting for around 50\% of drilling expenditure. The report concludes that a worldwide reduction of just 1 person per rig could result in annual savings of $\$ 10 \mathrm{M}$ in drilling expenditure.

\section{Near-Term: Reduce Time to Top-of-Reservoir}

In the near term also, the industry will concentrate on the first stage of drilling, i.e. performance drilling from surface to top of reservoir (where the metric is cost per unit distance).

\section{New Bits, Motors, and Drilling Fluids}

Steerable downhole motors ${ }^{16}$ have enabled substantial achievements in horizontal drilling. In the coming years, we expect that non-steerable motors will also see increasing use as performance aids for getting down to the reservoir, even in the vertical section, as well as drilling inside it.

The nature of the drilling fluids can also make major contributions to reducing drilling times and costs. Oil and synthetic - based (invert emulsion) muds still have several advantages over waterbased fluids - inhibition of water-swellable shale wellbore stability problems, high lubricity in deviated ERD wells, low filtercake sticking risk - but are increasingly being ruled out by tighter environmental legislation, led by offshore locations like the North Sea and the Gulf of Mexico. Whilst great progress has been made in recent years in finding water-based fluids which can compete on performance ${ }^{23}$, there is still some way to go. The advent of horizontal wells, deeper hotter wells etc. has put additional challenges on drilling fluid performance, requiring faster gelation on cessation of flow, improved rheology for effective cuttings transport and hole cleaning and the ability to maintain rheology and low fluid loss to permeable formations at increasingly high temperatures and pressures. Current temperature requirements extend to $350^{\circ} \mathrm{C}$ and are expected to rise further over the next decade.

All this demands increasingly smart and responsive fluids, and an enhanced understanding of structure-property relationships for complex fluids built from polymer/colloid/surfactant and other self-assembling building blocks. This represents an exciting challenge for materials chemistry. Here too simulation can aid experiment to find optimal solutions more efficiently. Figure 12 demonstrates the use of molecular dynamics simulation in search of new polymerbased aqueous drilling fluids. The rectangular, evenly spaced slabs are layers of montmorillonite, a swelling clay found in many chemically-reactive shales. In the example shown, the polymer chains anchor onto the clay surface to bind the layers together as well as forming a partial barrier to water invasion. Such simulations have proved highly effective in identifying the most appropriate chemical structures, reducing the number of potential additives that need to be screened experimentally, accelerating development times and reducing costs. 


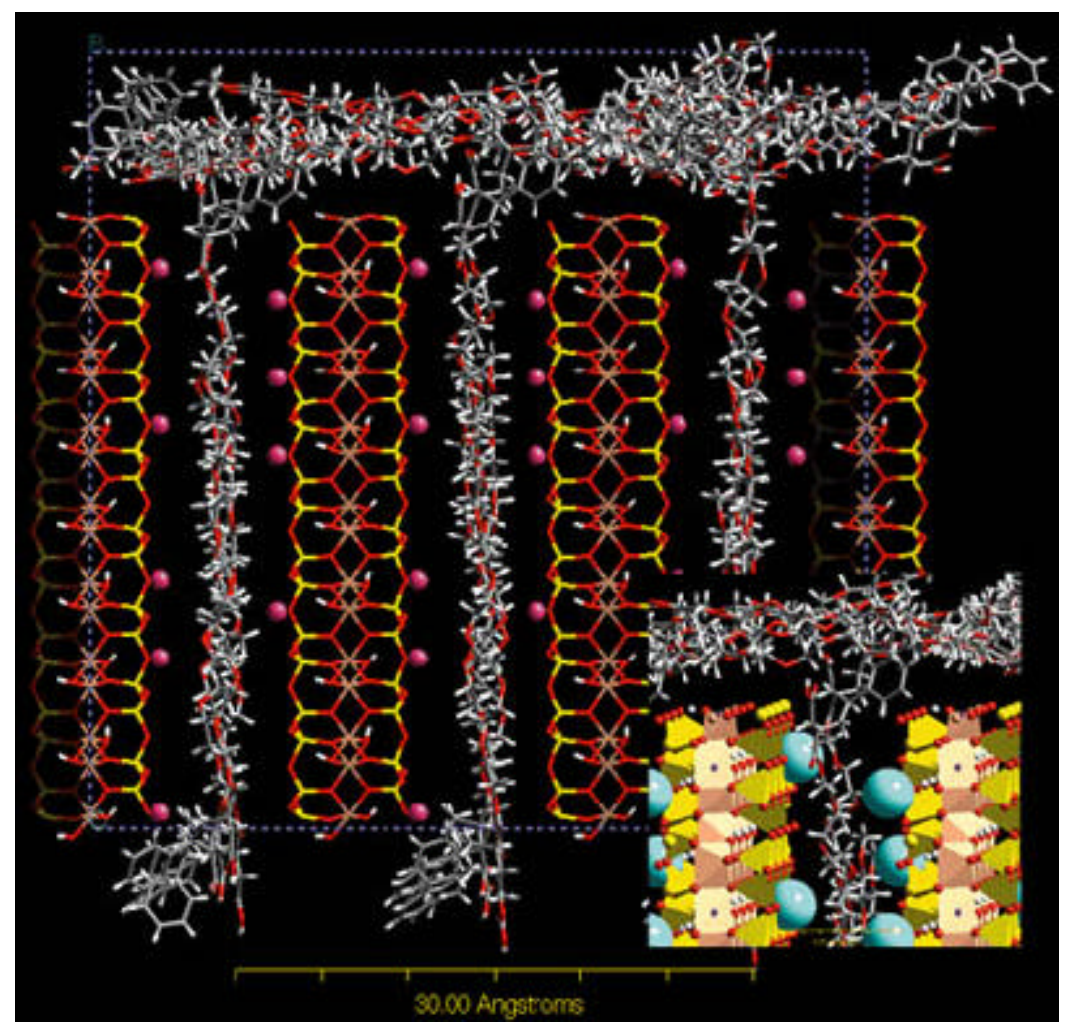

Figure 12. Image from a molecular dynamics simulation of the interaction of a polymeric drilling fluid with montmorillonite, a swelling clay found in many chemicallyreactive shale rocks. The fine pores between the evenlyspaced clay layers (consisting of regular tetrahedral and octahedral structures of silicon, aluminium, magnesium and oxygen atoms) are initially filled with water molecules. If the clay is just exposed to an aqueous drilling fluid, more water enters the pores and swells the clay to the point where it weakens and fractures or washes away. The long polymer chains, initially in the drilling fluid outside the clay, replace the water molecules between the clay sheets, binding the layers together and forming a protective barrier on the surface of the clay. Simulations of this type can be used to optimize the structure of oilfield fluid chemicals for many applications, reducing the amount of trial-and-error experimentation required and increasing the chances of defining reliable solutions.

\section{Eliminate Connections \& Trips}

A central problem today is that, overall, too much time is consumed on non-drilling activities. It is not unusual to find that only $30 \%$ of the total time available is spent in drilling. Another $30 \%$ may be spent in tripping - taking the drillstring in and out of the hole in order to insert a casing/liner, to log or carry out other operations. Whilst great progress has been made making measurements while drilling, a long term goal must be to carry out as many other operations as possible while drilling, leading to a single, uninterrupted, continuous well construction operation. Replacement of the current 4-5 section telescopic well ${ }^{27}$ by the monobore well, from surface to reservoir, should offer many advantages in terms of cost (time and materials) and producibility (size determined by the reservoir capability and production needs rather than by the number of sections of telescopic wellbore required to maintain hole stability in weaving between the various geophysical constraints of rock strength and pore pressure, using today's intermittent and sequential technology). To achieve this will require the development of continuous drillpipe, new drilling techniques, ways to line the borehole continuously while drilling etc., which present exciting challenges in mechanical and process engineering and in materials science. Such processes will involve simultaneous mechanical, fluid mechanical and chemical operations and their successful deployment will require good process models and appropriate downhole sensors and smart alarms for real-time monitoring and control. The separate fluids used in today's well construction - drilling, cementing, completion - will need to be replaced by multifunctional, smart, responsive well construction fluids whose properties can be locally optimized at different stages of the operation.

A number of projects have begun to address these issues. Experiments have been carried out with 
a number of alternative lining technologies, including expandable steel tubulars ${ }^{28}$ and downhole cross-linkable resin sleeves $^{29}$, which aim to save one or more casing strings, the first step towards the monobore continuously-lined hole. We have already mentioned the major impact of coiled tubing for drilling and other operations; we can expect further progress in reeled systems generally ${ }^{30}$, particularly for well lining.

As simultaneous operations for well construction become the norm, we can expect a continuation of current trends in logging measurements - less wireline logging and more formation evaluation while drilling. Tools will be developed which are capable of looking ahead and around the bit and so becoming an active part of the real-time trajectory selection process; current resistivity-at-thebit images $^{31}$ are early examples of this.

\section{Accelerate Learning Curve - Integrated, Multi-disciplinary Teams}

Key to improving performance is accelerating or steepening the learning curve: taking advantage of all information available from across the organization, including that available from the first well drilled in an area, to compress the learning time. Currently, it typically takes 5-10 wells drilled in a new area to optimize the process. If an approach based on smarter real-time measurements and better information management and interpretation is successful in the extreme, the second well drilled becomes as efficient as the $n^{\text {th }}$ well. Furthermore, the learning is then robust with respect to changes in the team, the environment, etc.. It is well understood that multidisciplinary integrated teams with aligned goals are vital to this improvement. Over time we expect non-traditional drilling technology, such as data mining, virtual reality, global communication, and 'push' technology (webcasting) will play a strong role as well. Imagine replacement of isolated specialists by multi-disciplinary teams taking immediate advantage of the best knowledge and experience available worldwide - drillers become knowledge workers.

\section{Long Term: Deliver Optimal Access to Undamaged Reservoir}

The second stage of drilling is drilling in the reservoir, where the metrics are number of barrels produced and profit per barrel. The end goal over the long term is not simply drilling 'deeper and cheaper' - it is delivering optimal access to the undamaged reservoir, a properly placed drainage system capable of producing to the maximum.

\section{Productivity / Economic Steering}

Productivity Steering or Economic Steering means that the future driller will have the capability to 'steer in economic space.' Imagine an alarm that lights up when the well has been drilled long enough to achieve the ROI target. BP has used an early version of this idea at Wytch Farm - a 'Cumulative Productivity Index (PI)' approach to defining the length of horizontal sections ${ }^{15}$.

\section{Install Reservoir Plumbing}

We can expect well construction to evolve into something that looks much more like installation of reservoir plumbing (or keyhole surgery). One can imagine a small number of conduits to surface, with many complex laterals, which are analogous to the plumbing of a city. The overall design problem must determine the optimal number, location, and makeup of laterals. The reservoir characterization/modeling and drainhole creation processes hence become intimately related and inter-dependent. The CAD techniques developed for process engineering should find 
increasing application here.

New logging-while-drilling tools which permit the driller to see ahead and around the bit will have major applications once in the reservoir, enabling him or her to optimize targeting and minimize undulations in horizontal laterals. The 'piping' may be conveyed with tractors, moles, or robots. It could also be installed via coiled tubing jetting to achieve ultra-short radius drainholes, kicked off in the reservoir. All these prospects come under what Shell in their vision of the future ${ }^{32}$ term 'Smart Wells.'

\section{Closed-Loop Drilling Process Control Real-Time Shared Earth Model Update}

All this is moving towards the capability to implement closed-loop drilling process control. The reservoir and the drainhole creation process become sufficiently well characterized and monitored for the whole activity to be under real-time automatic control. Key here is the linkage to the Shared Earth Model for

1. continuously monitoring of where we are in the reservoir versus where we want to be;

2. updating the model (including the overburden) as new data are acquired, and

3. modifying the well plan and trajectory to optimize reservoir drainage.

Putting this all together, we can envisage the scenario shown in the cartoon of Figure 13. The same illuminated areas remain from Figure 6. Contours on the surface of the reservoir illustrate zones interpreted as being of economic interest. A simple multi-lateral well has been drilled, around which an illuminated halo sheds more light (from LWD/MWD log data acquired during drilling). A third lateral is being drilled by a significantly smaller rig than in the first cartoon. The countryside encroaches on the rig, and nearby are surface facilities to deal with production from the evolving drainage system. Whereas the first rig in Figure 6 had several satellite sites (mud tanks, MWD shack, driller's hut, engine room, etc), the second is much smaller and has only one room attached - generally illustrating the merging of disciplines (e.g., mud + cement), and use of the same mechanics for all functions.

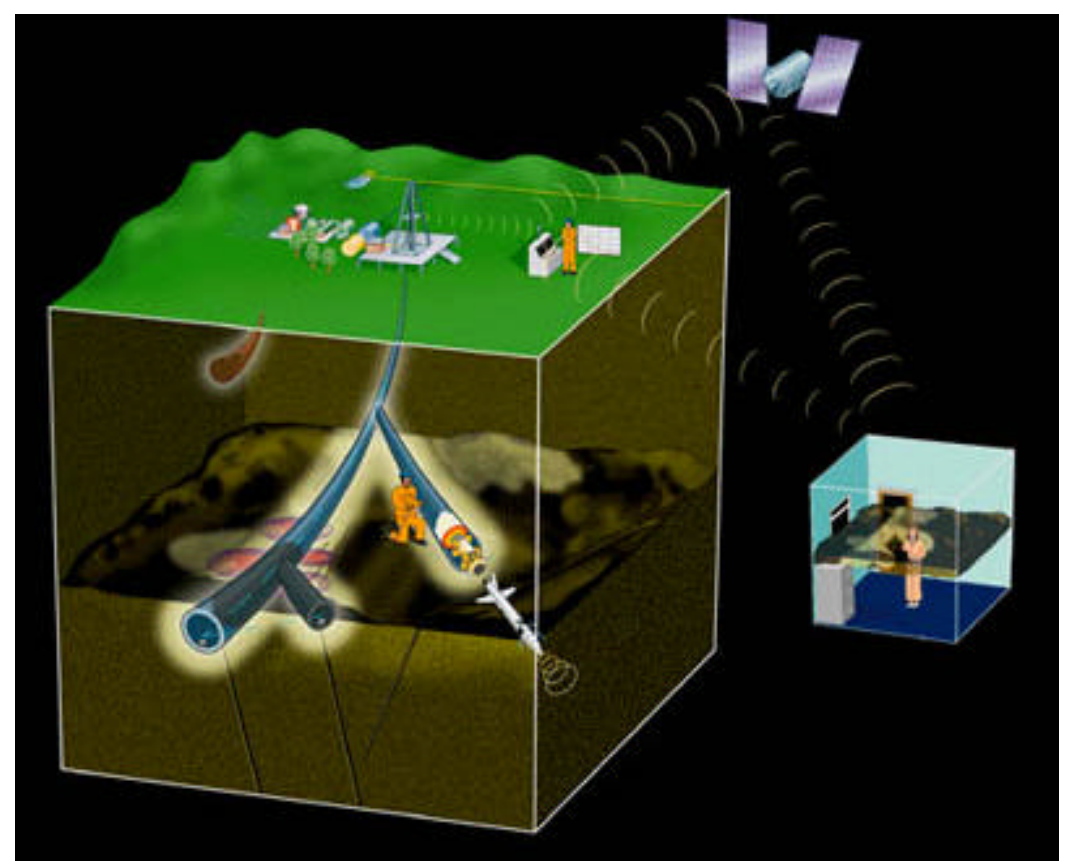

Figure 13. Well Construction cartoon, showing how the reservoir and surface facilities might look as well construction evolves towards reservoir plumbing.

We see smart drilling technology involved in guiding rapid, accurate, controllable installation of the drainage sytem. This is illustrated by a cruise missile seeking out a productive/economic target ahead. The missile is 'illuminating' the reservoir as before (illustrating the data being acquired). Behind the 
missile, in the hole made by it, is a double ended, wheeled, 'crawler' with a spraying head on the front coating the well bore with a new borehole lining material and a flame thrower at the back, baking the material. A tributary pipe or valve is being installed on the liner behind the crawler 'reservoir plumbing'.

The mission control room receives data from the missile and other sensors and sends instructions back. The reservoir is becoming increasingly well lit and the room full of visualization is becoming more complete with its colored-textured virtual image of the reservoir, on an increasingly complete volume. We also see a drilling supervisor on the surface, with the learning curve for the area in evidence.

\section{Well Productivity Optimization: Towards Lifetime Optimal Productivity Index, Fluids, and Data Delivery}

Now we move on to the second crucial operational step: having created the optimum well structure and connectivity to the reservoir, ensuring that production from the reservoir continues to be optimal throughout its lifetime, responding to changes both in the downhole environment as the reservoir evolves during production, and in hydrocarbon requirements at surface, the marketplace. The roadmap for how this Well Productivity Optimization stage might evolve is shown in Figure 14.

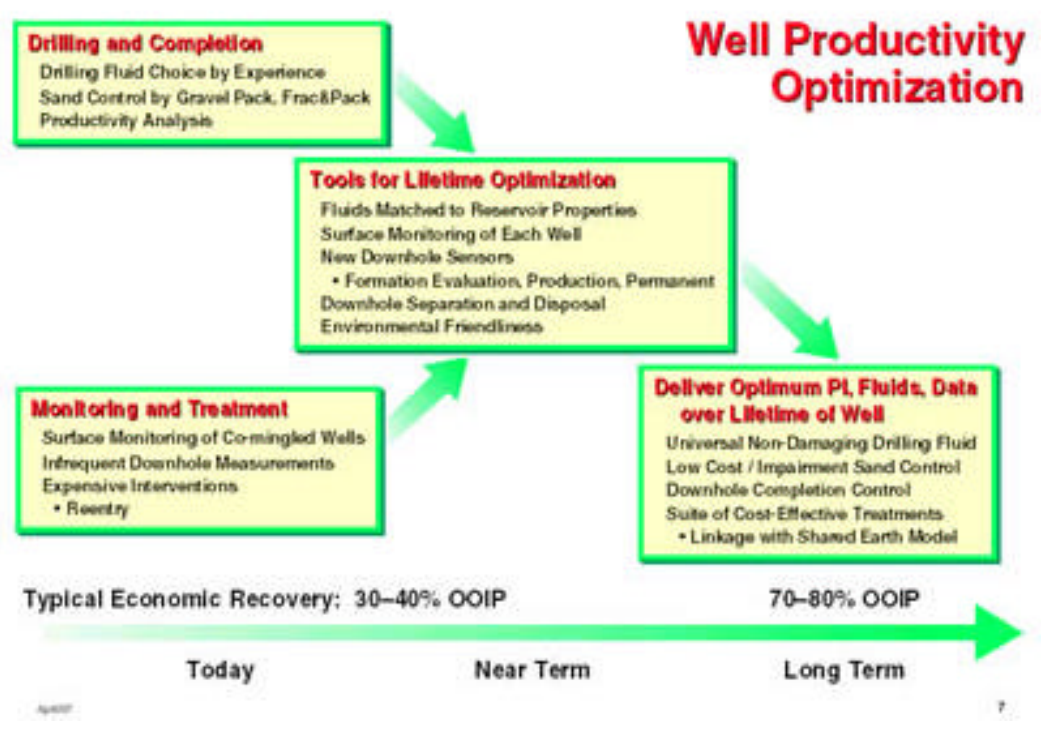

Figure 14. Roadmap showing the possible evolution of Well Productivity Optimization.

\section{Existing Technology}

On the left-hand side, we show today's state of the art from two points of view: Drilling and Completion, and Monitoring and Treatment.

\section{Drilling and Completion}

We have already referred to the key role played by the choice of drilling fluid and drilling practice (overbalanced vs underbalanced) in the reservoir in minimising permeability impairment, particularly for open-hole completions (where a casing is not cemented in place and subsequently perforated with explosive charges, but the hole simply supported by a slotted liner or porous screen). Drilling fluids vary from the simple to the complex ${ }^{33,34}$, presenting drillers with 
significant choice and the need for appropriate fluid selection and management. Fluids engineering, adopting a holistic approach which includes fluid mixing, placement, monitoring, modification, recycle and disposal in addition to the chemistry and physics of fluid design, will become an increasingly important aspect of well and reservoir operations. Progress has already been made towards this goal ${ }^{35}$ but much remains to be done. Designing the ideal fluid is a complex optimization, varying with the nature of the formation, well trajectory, drilling practice and nature of the completion. Unfortunately, it is still true today that many mechanisms underlying fluid functional properties and their interaction with rock materials are not well understood. Much fluid selection is based on experience, and often a partial view of the hydrocarbon extraction chain, rather than a holistic approach that combines management of previous data ('experience') with composition-structure-property relationships and design constraints imposed by the reservoir model and the well construction strategy.

A significant problem with poorly consolidated formations is the production of sand alongside the fluids ${ }^{36}$. Current practice is to diagnose potential sanding zones and to use completions that prevent sand from entering the well. Two commonly used options are gravel packs, which create a fine porous filter adjacent to the wellbore wall, and frac\&pack, whereby short fractures (usually less than $30 \mathrm{~m}$ long and up to $3 \mathrm{~cm}$ wide) are created by applying hydraulic pressure through the perforations with high viscosity fluids carrying (in this case high) concentrations of sand or ceramic particles ('proppant'). The short, wide fractures become packed from tip to wellbore with proppant which subsequently acts as a near-wellbore screen.

The completion must be designed to optimize productivity given the nature of the reservoir, fluids in place, geometry of the well etc. Productivity analysis software, based on nodal analysis techniques, is commonly available for predicting the flowrate/ pressure drop characteristics of a given completion scenario.

\section{Monitoring and Treatment}

Today, the common practice is only to monitor fluid production at surface from co-mingled wells; the flow from individual branches of multilaterals is not measured. Typically, to understand accurately the composition of the flow produced by an individual well requires installation of a separator. Three-phase (oil-gas-water) meters are still in their infancy; key issues are cost and the ability to deal with a wide range of flow rates and amounts of gas.

Downhole production logging tools are becoming increasingly sophisticated in their ability to measure both individual phase flowrates and the structure of the multiphase flow ${ }^{37}$, but they are still used relatively infrequently compared to surface monitoring because of the high cost involved. A key reason behind the expense of downhole measurements is the need for re-entry. Production logging in long horizontal wells ${ }^{38}$ may entail up to 10 days of coiled-tubing time, an expensive operation. As with diagnosis of a production problem (low oil production, unacceptably high water entry), so with the corresponding treatments designed to increase productivity $^{39}$, such as fracturing, matrix acidising or reperforation. These too involve expensive re-entry operations and the combined cost of diagnosis/treatment must be amply compensated for by improved production to justify their implementation.

\section{Near-term: Tools for Lifetime Optimization}

In the near term, we foresee the development of tools for lifetime optimization of well 
production. Drilling and completion fluids will become better matched to reservoir properties. (Figure 15 shows shows the importance of engineering drilling fluids solids particle size for optimum pore bridging and external cake building ${ }^{40}$.) This presumes the accurate characterization of mud/completion fluid damage; today the industry does not have a tool for measuring the damage done to the reservoir by the well construction fluids. A proper measure would help with reservoir characterization and in characterising the real value brought by the drill-in fluid engineering.

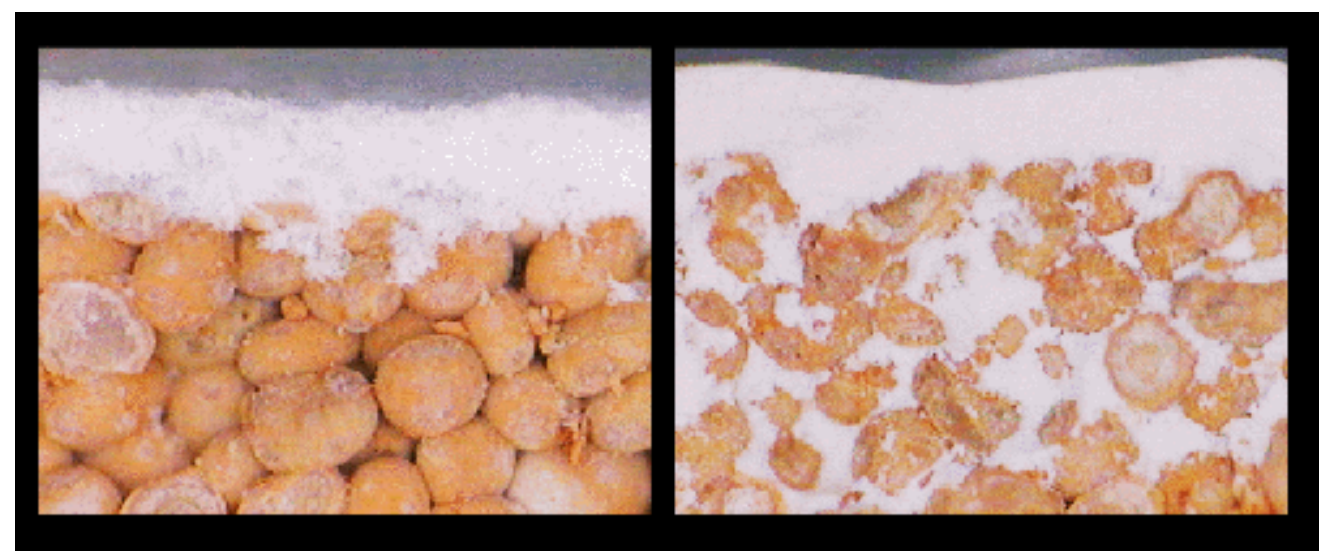

Figure 15. Electron micrograph images showing the importance of engineering drilling fluids particle size for optimum pore bridging and external filtercake formation to avoid formation damage in the reservoir. The rock is Ketton Limestone, having a permeability of 2 Darcy and pore throats about 75 microns in diameter. The left hand image shows a non-damaging mudcake produced from a drilling fluid using coarse calcium carbonate. The image on the right shows the effect of using a finer carbonate, mismatched to the reservoir rock and thus leading to considerable damage and permeability impairment.

\section{Surface Monitoring and Downhole Sensors}

The intensive effort on three-phase metering should lead to economical and robust meters in the relatively near term. New downhole sensors are being developed for both cased and open-holes, to monitor the evolving state of the reservoir and production. Permanent sensors are already being deployed $^{41}$. For instance Statoil have installed a pressure monitoring system in the Gullfaks and Veslefrikk fields; data recorded by permanent gauges is transmitted by satellite to oil company offices for use in reservoir modeling. The problems to be solved in this area are many, including power, telemetry, and miniaturization. It is also interesting to conjecture that autonomous vehicles - robots - may some day query and service the sensors.

\section{Downhole Separation and Disposal}

A significant part of oil recovery costs arise from the need to separate oil from produced water on surface. A growing target is to only return selected hydrocarbon to surface by implementing downhole separation procedures ${ }^{42}$, and reinjecting the unwanted water or gas into the reservoir, preferably in a manner which aids the reservoir pressurization and sweep efficiency for further secondary recovery of oil. The challenge here is to transfer water/hydrocarbon separation processes, standard within the petrochemicals and other process industries, into compact, costeffective devices capable of operating deep within the wellbore plumbing network. Coupling to the reservoir model is of course essential for planning the location of disposal wells to optimize the benefits of reinjection. All this will help reduce the environmental footprint of the extraction operation, both in terms of returned fluids and external facilities. 


\title{
Long-term: Deliver optimum productivity index, fluids and data over well lifetime
}

\author{
Universal Non-Damaging Drilling Fluid
}

The long-term goal is to deliver the optimum Productivity Index (bbl/day/psi/ft), fluids and data to the surface over the lifetime of the well, delivering to the surface only the fluids that are wanted. Delivery to the surface of data that will assist in reservoir management is also extremely important. As already anticipated, we may expect to see 'universal' non-damaging well construction fluids - perhaps adaptive fluids that are able to match their characteristics to drilling and reservoir conditions, which may be linked to measurement and adaptive control systems, either at surface or downhole.

\section{Low Cost/Impairment Sand Control}

Improvements in sanding prediction procedures ${ }^{36}$ will be exploited through the development of selective treatments. Rather than simply preventing sand reaching the wellbore, methods need to be found to consolidate weak producing formations whilst maintaining their producibility - either through maintaining their intrinsic permeability or introducing alternative high permeability pathways through the consolidated rock.

\section{Downhole Completion Control}

Today, what downhole control there is over production from individual laterals is quite simple. Typically, mechanical intervention is required to exert control. In the long-term, we can expect much more factory-like control in the subsurface, with instrumented completions enabling the branches and sub-branches of the drainage system to be shut-in or brought on stream through valves operated remotely by Production Control.

\section{Suite of Cost-Effective Treatments}

In order to maintain the well productivity at high levels, it will be essential to have accurate diagnosis procedures for the cause and location of production problems, be they an overall decline in produced fluid rates or increasing amounts of unwanted water or gas. This will require accurate and localized production logging and formation damage monitors - permanent sensors within the well and the reservoir. The appropriate treatment procedure will be selected on the basis of technical match to the diagnosis and its cost-effective impact on the well productivity, through linkage back to the reservoir production models.

The suite of available treatment procedures will be expanded from those currently available in various ways. New fracturing fluids will be developed which deliver $100 \%$ retained permeability within the fracture and can operate over wide ranges of formation permeability and reservoir temperature. New matrix treatments will be developed which replace the existing unfriendly acid fluids ${ }^{43}$ by new milder and selective solvents, which remove drilling and production damage to restore or enhance reservoir permeability. The creation of scale through the precipitation of normally insoluble salts like barium sulphate and calcium carbonate in the near wellbore formation and the production tubulars has a major impact on well production. Scale control is today effected by injection of precipitation control agents into the reservoir ${ }^{44}$; their release is controlled over a period of several months by adsorption and slow dissolution processes within the reservoir ${ }^{45}$, but the period between treatments (costly both in the materials used and the 
production interruptions they cause) is still quite short, typically 6-18 months. In time we will see scale treatments that last for years; the challenging target for current research is a single treatment that lasts the lifetime of the well.

Water control, or conformance control ${ }^{46}$ as it is increasingly widely called, is a technology that is crucially dependent on good problem diagnosis in order to match the treatment to the root cause...water can enter a wellbore for a wide variety of reasons, some associated with the integrity of the near-wellbore zonal isolation, others with the detailed topology of the reservoir and the placement of the well within it. Potential solutions include fracturing, shutting-in existing wells and drilling alternative laterals, local drainholes and gel injection. Gel treatments ${ }^{47}$ have had mixed success to date, mainly because of uncertainties in exactly where to inject the gelling fluid or to what depth and due to the lack of control over exactly where the gel flows to in the reservoir before it sets. Sometimes oil zones become blocked as well as water zones or improvements in oil productivity are transient as injected water eventually bypasses both the gel barriers and the oil. In the future we will see smart conformance control systems, that are relatively insensitive to the detailed reservoir topography for their effectiveness and selectively enable the production of oil. The ultimate goal, of course, will be to produce only oil into the wellbore, transferring downhole separation from the current target, the wellbore, back into the reservoir.

Another issue for cost-effective treatments is zonal isolation. In long horizontal wells with openhole completions, it is currently not easy to isolate the section of the well responsible for unwanted fluid entries, as it is for conventional cemented and perforated wells. If it proves necessary to seal off the well from its toe up to the position of entry, then a large fraction of the productive area of the well will be lost. So increasing efforts will be required to develop systems which can isolate problem sections of a well, enable a local treatment to be carried out (gel injection, matrix treatment, fracturing etc) and then restore the whole of the well back to full production at its original or enhanced level. An example of an early approach to this is the use of new types of settable thixotropic fluids to place annular packers (sealing plugs) to give local zonal isolation in slotted liner completions ${ }^{48}$ - see Figure 16.

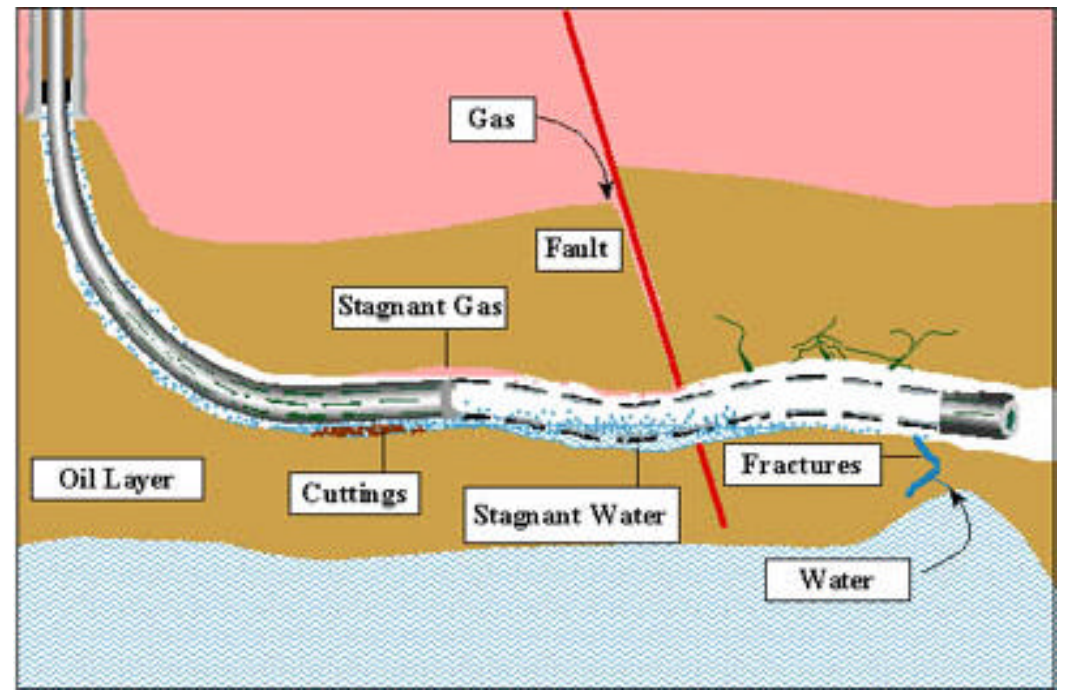

Figure 16. (a) Typical production problems encountered in horizontal wells completed with uncemented slotted liners to maximize fluid production. Initially the produced fluid is mainly oil, but eventually the entry of unwanted water or gas, through fractures or faults or high permeability streaks in the reservoir can make production uneconomic. The unwanted fluid entries can only be sealed off by filling the wellbore with e.g., cement from its toe up to the entry point, resulting in loss of a large portion of the well's producing area. 
Figure 16. (b) One way to treat the problem is to place chemical plugs behind the slotted liner, one on each side of the water or gas entry point. These isolate this small section of the well to enable cement or other sealing fluid to be pumped into the fracture/fault to seal off the unwanted entry, without losing production from the downstream section of the well.

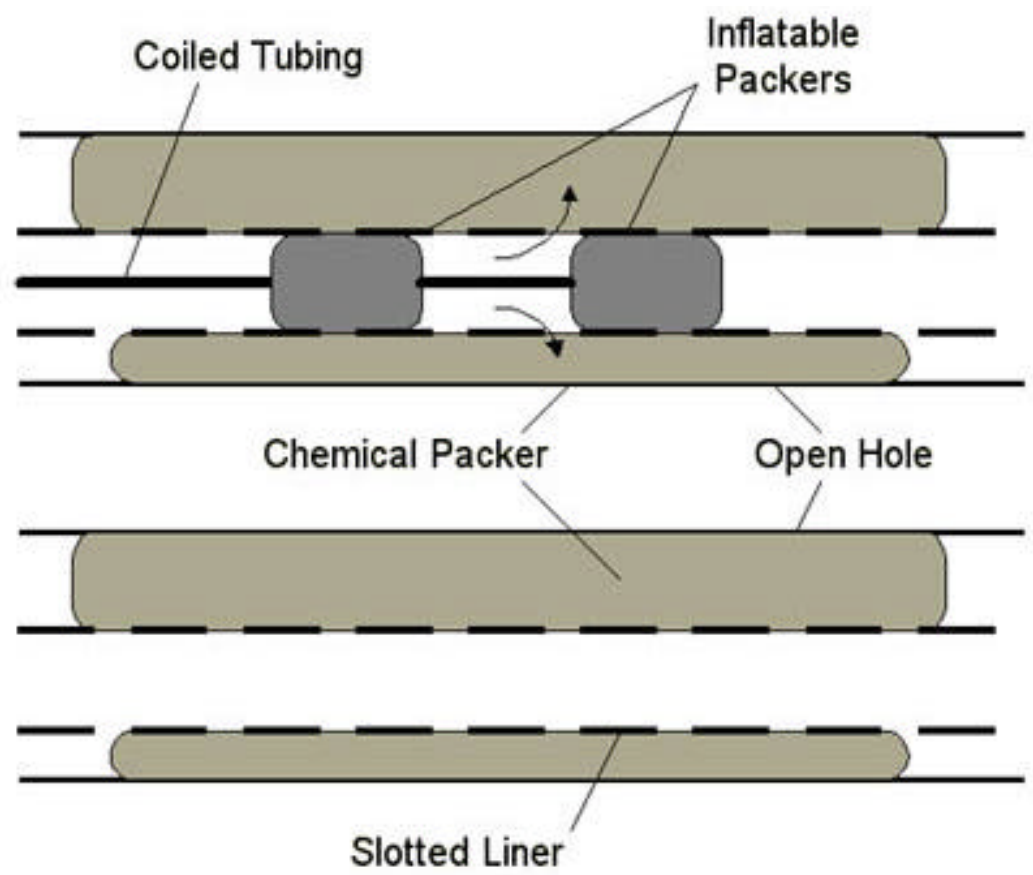

\section{Linkage with Shared Earth Model}

In addition to the crucial role played by the shared earth model in selecting and optimising well treatments, there will be a significant market niche for software tools designing intelligent completions, using simulation to determine for each case the optimum type, number, and placement of sensors and controllers in laterals and at branch points. As with all of the software components in these roadmaps, ease of use and the capability for seamless integration with other software will be as important as the robustness and accuracy of the underlying algorithms.

The picture of well operations that emerges from this is shown in Figure 17. Here the original multilateral has grown additional branches. One multilateral branch has a circumferential pressure sensor and a flowmeter and can be controlled by a valve ('sensor like' fittings on the pipes). A downhole separator is shown with three units: one separates oil and water, one feeds water to a well branch in contact with the aquifer (downhole disposal) and the third one sends the oil onward to surface in the well. Other multilateral branches could be drilled into another zone (aquifer for disposal, gas for lift etc.). 


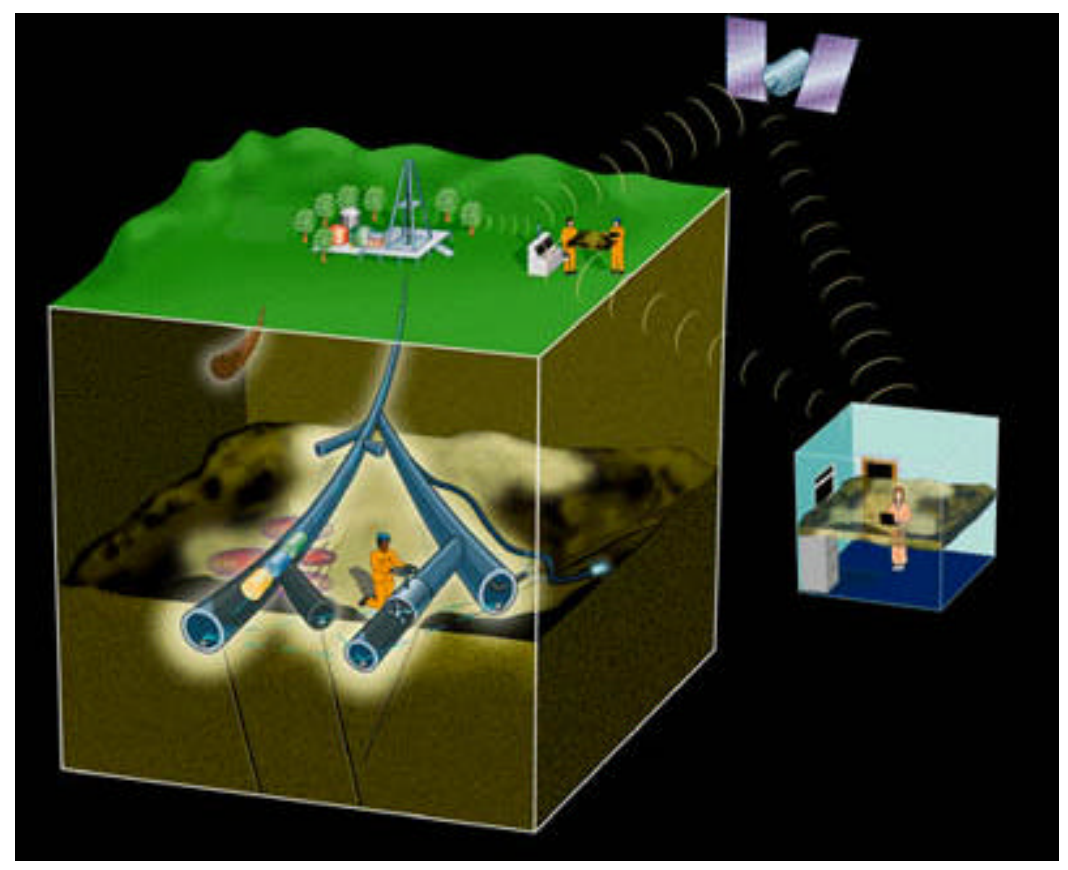

Figure 17. Cartoon illustrating how downhole and surface operations might appear with the development of new technology for Well Productivity Optimization.

Sensors in each of the branches continue to send data about the well to surface production control. A new sensor is being installed in one of the branches. The sensors include crosslateral sensors (e.g. acoustic or chemical or electromagnetic). Signals travel between branches and to the surface (up and down).

On the surface, two characters also have access to the shared earth model to devise appropriate treatments. An ultra-short radius drainhole is being drilled via coiled-tubing jetting. The reservoir illumination is getting better in the region of the downhole sensors (time-lapse pressure data). Data acquisition from the permanent sensors is shown by radar/sonar-like pulses around the sensor. The refinery/factory has moved to surround the rig and wellhead which occupies a smaller area, surrounded by trees.

\section{Real-Time Reservoir Management: Towards the Reservoir as a Factory}

Figure 18 shows the final roadmap, illustrating how, once we have the means to optimize the reservoir model, well construction and well productivity, we might evolve towards the ultimate goal of real-time reservoir management.

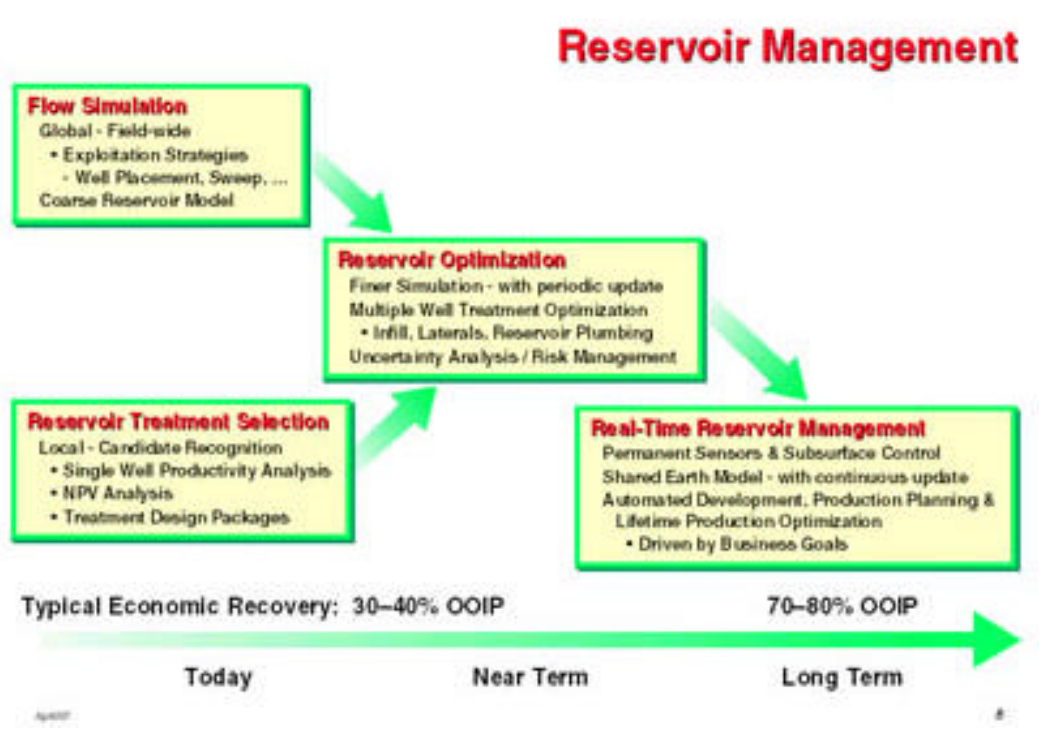

Figure 18. Roadmap for the possible evolution of Reservoir Management. 


\section{Existing Technology and Practice}

On the left-hand side, we consider today's approach to Reservoir Management from two points of view: Flow Simulation and Reservoir Treatment Selection (i.e. what can be done in the field to improve recovery and production rate). We have already discussed the state of the art and improvements expected in measurements and reservoir (Shared Earth) models on previous roadmaps.

\section{Flow Simulation}

Today, primary well placement is determined on the basis of reservoir characterization linked to field-wide simulation ${ }^{9,49}$ and a knowledge of the drive mechanism - gravity, solution gas, water influx or compaction. The coarse reservoir model is the basis of flow simulation and upscaling is standard, being supported by several software packages.

\section{Reservoir Treatment Selection}

By contrast with the global character of flow simulation for well placement and sweep, treatment selection (e.g. stimulation) is largely based on identifying individual wells as candidates using criteria linked to Net-Present-Value analysis ${ }^{49}$. Commercial software exists for simulation, candidate recognition, and treatment design. For instance, plots of horizontal permeability across a field can be used to identify the best candidate wells for matrix acidising. Figure 19 shows a Net-Present-Value analysis for a fracturing job, and how the benefits vary with formation permeability and fracture depth.

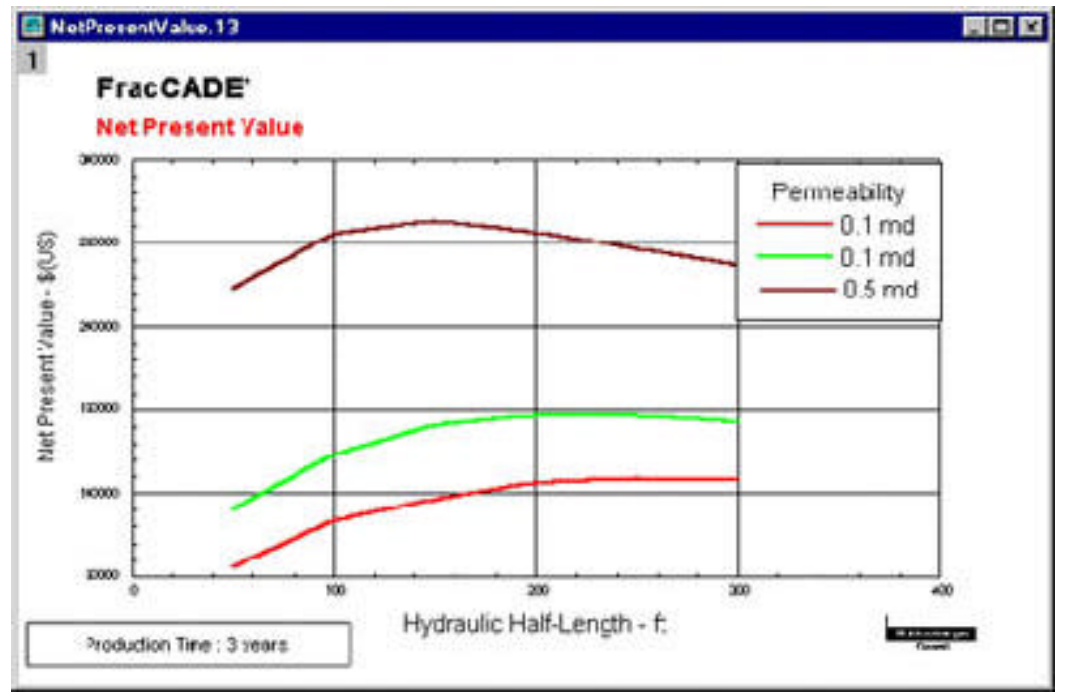

Figure 19. Example of a Net Present Value (NPV) analysis for a fracturing job.

A variety of treatment/fluid design packages exists, though these are usually used prior to a job rather than for real-time optimization and control. They require solid mechanics models of the reservoir rock, fluid mechanics models of the fluid placement and modules for variation of fluid properties with well and reservoir

conditions. It is expected that such process and fluid models for all these operations will become increasingly refined and user-friendly over the coming years, as both improvements in the underlying physics and available computer power are exploited to produce real-time interactive software.

The task of producing accurate and speedy simulations of reservoir treatment processes is perhaps even more challenging than for reservoir simulation since here, unlike in production flows, the injected fluids are non-Newtonian, sometimes viscoelastic and have properties that may vary with time or with chemical environment. In this area, there are great possibilities for pore-scale simulations to be combined with simulations on the reservoir scale, so as to capture the 
consequences of complex small-scale flow processes on the behavior of the reservoir as a whole. While the multiphase extension of Darcy's law may be adequate for simple oil-water production flow displacements, there is little doubt that this description will prove inadequate when we come to simulate treatment flows in which viscous forces and evolving fluid properties are central to the functioning of the process.

\section{Near-term: Reservoir Optimization}

In the near term, the industry is moving towards a situation where data from a variety of sources and length-scales (near-wellbore to full reservoir) will be integrated to give enhanced reservoir models. Risk analysis and uncertainty management will also be incorporated and combined with the reservoir models for design of multiple-well treatment-optimization programs, where 'treatment' may include infill and lateral well placement.

Increasingly sophisticated production monitoring techniques and software will provide the data and 'glue' necessary to allow reservoir models to be updated periodically as the field is produced. The parallel development of multilateral drilling and completion technology, together with increasingly selective treatment methodologies, will enable this improved reservoir characterization/simulation capability to be exploited to the full. Multidisciplinary teams which cross both technical specialities and the technical/marketing/business boundaries are an increasingly key part of this holistic approach.

For instance integrating surface network simulators with reservoir simulators will enable production managers to minimize capital investment in surface facilities, optimize flow, and finetune field planning. Multiple well treatment optimization packages will be developed which couple reservoir simulators to economic and business models to evaluate the relative merits of alternative treatment scenarios. Uncertainty analysis and risk management will be increasingly integrated into the decision processes.

IT has already had a major impact on the practice of all phases of geoscience - geology, geophysics, petroleum engineering, reservoir engineering, and data management ${ }^{50}$. As in many industries, it is also beginning to have an impact on the financial, business, and operational aspects of the E\&P sector. Many companies are struggling to implement business software packages across their product lines and geographic areas; business software developers have by and large not had the experience to consider the global reach of the oil industry, with its abundance of transnational operations, currencies, and so on. So, though the potential is high, much remains to be done here too.

\section{Long-term: Real-Time Reservoir Management}

In the longer term, we can expect major advances in permanent sensors, together with advances in computational, communications, SCADA (supervisory control and data acquisition) and simulation technology. In conjunction with the advances in reservoir models and fluid mechanical simulation discussed earlier, these will enable continuously updated fluid-movement maps and an integrated package for real-time reservoir control. Coupled with further advances in drilling, completion, and treatment technology, this will lead to automatic generation and analysis of well placement and treatment scenarios and will enable production decisions to be optimized in the context of operator business goals. By this point, geoscience, process engineering and business software are seamlessly integrated - business simulation is linked with reservoir simulation. 
Achieving the long-term goal requires effective integration of data, software, responsive mechanical and fluid technology and multi-disciplinary teams. Putting this all together, we see real-time reservoir management as the norm. For example one can envisage scenarios where cross-lateral measurements are being made with permanent sensors. As water enters the lowest of the lateral branches, and reaches a critical control valve, this lateral is closed in to minimize water production. At a later stage, decisions might be taken to reverse the process and inject water into an already flooded lateral to displace oil towards other arms of the reservoir drainage system. Reservoir treatment and intervention only become necessary once options involving manipulation of the existing underground network have been exhausted.

And so in Figure 20 we reach the final cartoon of how an oilfield location might look in the realtime reservoir management era. The separator is still downhole, but the surface facilities have also slipped below ground level. At surface now is a petrol station; a highway leads to the station where processed products are delivered after downhole processing. The countryside is only marginally impacted by the facility which is part of a small conurbation. Apparently, we now have a 'pore to pour' operation.

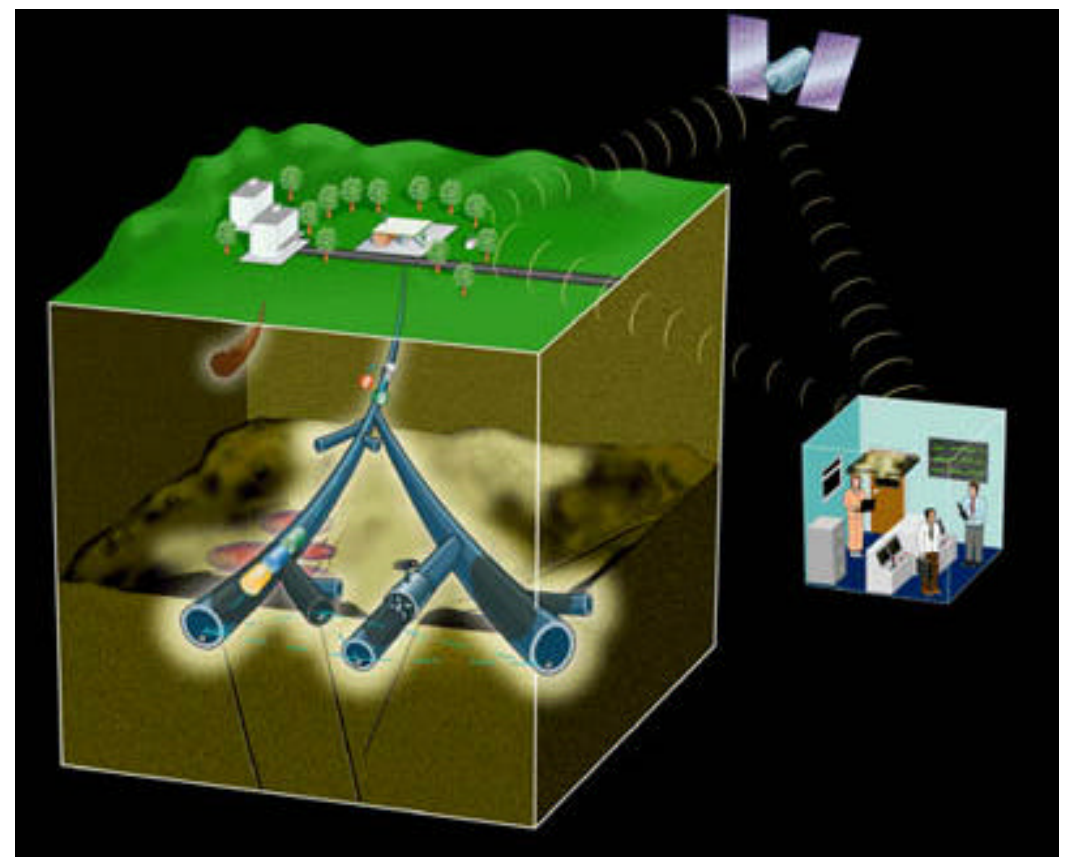

Figure 20. Cartoon showing a possible oilfield location in the era of real-time reservoir management.

The last trace of local 'mission control' is an aerial in the woods sending data back to the immersive visualization room, now occupied by a business manager analysing graphs (backed up by a financial specialist and a geoscience specialist, although the latter has slipped into the background). Feedback communication from the immersive visualization lab to the wellhead control, a valve system at surface, and a valve downhole emphasize the fact that simulation is in the loop - the reservoir simulation is going on all the time, rather than as discrete runs.

The reservoir is now brightly illuminated and the visualization is very detailed and complete. At this point, we have a reservoir 'factory'; its individual pipeline reactors, each producing hydrocarbon product with a yield and purity that vary with time but in a way that can be closely monitored and controlled, are operated as an integrated system. The data are comprehensive and clear; the management task is fed by the data update.

\section{Conclusion}

This review has attempted to summarize existing practice in the hydrocarbon recovery (exploration and production) sector of the oil industry, and to suggest possible scenarios for the way that the enabling technology and engineering might evolve over the next 10-20 years. We 
have done this by presenting technology roadmaps and cartoon future scenarios for four technology packages that together have the potential to enable a new era in productivity. It is envisaged that the oil reservoir of the future will evolve towards a subterranean factory, consisting of an interconnecting network of individual production units (wells or drainholes) which deliver only saleable hydrocarbon to the surface. This hydrocarbon production system will be closely monitored in situ and controlled from a remote nerve-centre which has responsibility for controlling and optimising production from many geographically dispersed assets. The reservoir (or system of reservoirs) will be exploited using a systems engineering approach, into which business considerations are seamlessly integrated, to ensure that the individual production units are deployed and modified in a way that optimizes the cost, amount and nature of produced hydrocarbon required to match market needs and business strategy. Pro-active, real-time reservoir management will become the norm.

Such a summary must inevitably be incomplete and selective, but it is hoped that the major targets have been identified and that ways in which the process engineering and chemical technology communities, in particular, can contribute to shaping the future of the industry are clear. Achieving the goals described will require an overall industry effort - building on the work of operators, service companies, suppliers, SMEs, academics and government. Hopefully this paper will stimulate further dialogue and collaboration between all these groups to develop a technical agenda that turns the vision of real-time reservoir management into a reality.

\section{Acknowledgments}

The authors thank Schlumberger Oilfield Services for permission to publish this review, and gratefully acknowledge the assistance of all their many colleagues in Schlumberger who provided information and ideas that have been incorporated into the paper.

\section{References}

1. Campbell, C.J. and Laherrere, J.H., 1998, The end of cheap oil, Sci. American, March: 6065.

2. Al-Hussainy, R. and Humphreys, N., 1996, Reservoir management: principles and practices, J. Pet. Tech., 48(12): 1129-1135.

3. For example: Fayers, F.J. (ed.), 1981, Enhanced oil recovery, Dev. in Pet. Sci., 13, (Elsevier, Amsterdam).

4. For example: Salter, A. and Thakur, G., 1994, Integrated petroleum reservoir management - a team approach (PennWell Books, Tulsa OK USA), pp 155-170.

5. Willyard, C.H. and McClees, C.W., 1987, Motorola's technology roadmap process, Research Management, Sept-Oct:13-19.

6. Semiconductor Technology Association, 1994, The national technology roadmap for semiconductors.

7. For a complementary view of the future see: Anderson, R.N., 1998, Oil production in the $21^{\text {st }}$ century, Sci. American, March: 68-73.

8. Ariffin, T., Solomon, G., Ujang, S., Bee, M., Jenkins, S., Corbett, C., Dorn, G., Withers, R., Ozdemir, H. and Pearse, C., 1995, Seismic tools for reservoir management, Oilfield Rev., 7(4): 4-17.

9. Albertin, I., Darling, H., Mahdavi, M., Plasek, R., Cederio, I., Hemingway, J., Richter, P., Markely, M., Oleson, J.-R., Roscoe, B. and Zeng, W., 1996, The many facets of pulsed neutron cased-hole logging, Oilfield Rev., 8(2): 28-41.

10. Adamson, G., Crick, M., Gane, B., Gurpinar, O., Hardiman, J. and Ponting, D., 1996, 
Simulation throughout the life of a reservoir, Oilfield Rev., 8(2): 16-27.

11. Pedersen, L., Ryan, S., Sayers, C., Sonneland, L. and Hafslund Veire, H., Seismics snapshots for reservoir monitoring, Oilfield Rev., 8(4): 32-43.

12. Allen, D., Crary, S., Freedman, R., Andreani, M., Klopf, W., Badry, R., Flaum, C., Kenyon, W., Kleinberg, R., Gossenberg, P., Horkowitz, J., Logan D., Singer, J. and White, J., How to use borehole nuclear magnetic resonance, Oilfield Rev., 9(2):34-57.

13. Balough, S., Betts, P., Breig, J., Karcher, B., Erlich, A., Green, J., Haines, P., Landgren, K., Marsden, R., Smith, D., Pohlman, J., Shields, W. and Winczewski, L., 1994, Managing oilfield data management, Oilfield Rev., 6(3): 32-49.

14. Bosio, J., 1990, Horizontal wells - on the up and up, Exploration and Production Technology International (Cornhill Publications, London).

15. Allen, F., Tooms, P., Conran, G., Lesso, W. and Van de Slijke, P., Extended-reach drilling: breaking the 10km barrier, Oilfield Rev., 9(4): 32-47.

16. Bigio, D., Rike, A., Christensen, A., Collins, J., Hardman, D., Doremus, D., Tracy, P., Glass, G., Bo Joergensen, N. and Stephens, D., 1994, Coiled tubing takes center stage, Oilfield Rev., 6(4): 9-23.

17. Hill, D., Neme, E, Ehlig-Economides, C. and Mollinedo, M., 1996, Reentry drilling gives new life to aging fields, Oilfield Rev., 8(3): 4-17.

18. Leising, L.J. and Rike, E.A., 1994, Underbalanced drilling with coiled tubing and well productivity, SPE Europ. Pet. Conf., (London, UK, Oct 1994): SPE 28870

19. Bru, J.G., 1997, Reserves potential, Euroil, Feb. 1997:14.

20. Schoenmakers, J.M., 1997, Introduction of game-changing drilling technology, SPE/IADC Drilling Conference, (Amsterdam, Netherlands, March 1997), 519-527, SPE/IADC 37635.

21. Kamata, M., Underhill, W., Meehan, R. and Nutt, L., 1997, Drill-bit seismic, a service for drilling optimization, Trans. SPWLA $38^{\text {th }}$ Annual Logging Symp. (June 15-18, 1997): paper DD.

22. Last, N., Plumb, R, Harkness, R., Charlez, P., Alsen, J and Maclean, M., 1996, An integrated approach to wellbore instability in the Cusiana field, SPE/IADC Drilling Conference (Amsterdam, Netherlands, March 1997): 37-43, SPE/IADC 37573.

23. Bailey, L., Reid, P.I. and Sherwood, J.D., 1994, Mechanisms and solutions for chemical inhibition of shale swelling and failure, Proc. $5^{\text {th }}$ RSC Intnl. Symp. On Chemistry in the Oil Industry (Ambleside, UK, 13-15 April 1994): 13-27.

24. Gault, A.G., 1996, Riserless drilling: circumventing the size/cost cycle in deepwater, Offshore, May 1996: 49-54.

25. SPE London and Aberdeen Sections, 1997, Shell Expro's first application of coiled tubing drilling declared a great success, SPE Review, 90: 14-16

26. Chapman, P., 1996, BP Downhole TALK, 63:1,12.

27. Michaux, M., Nelson, E., Vidick, B., 1989, Cement chemistry and additives, Oilfield Rev., 1(1): 18-25.

28. Stewart, R.B., Gill, D.S., Lohbeck, W.C.M. and Baaijens, M.N., 1996, An expandable slotted tubing, fire-cement wellbore lining system, SPE Ann. Tech. Conf., Denver (Colorado, 6-9 October 1996): SPE 36583, 127-134.

29. Saltel, J.L., Leighton, J., Faure, A. and Baaijens, T., 1996, In-situ polymerisation of an inflatable composite sleeve to reline damaged tubing and shut-off perforation, Offshore Tech. Conf. (Houston, Texas, 6-9 May 1996): SPE 8202, 487-495.

30. Shell International Exploration and Production B.V., 1996, Reeled systems technology: transforming coiled tubing into a complete E\&P system, SIEP 96-5285.

31. Bonner, S., Fredette, M., Lovell, J., Montaron, B., Rosthal, R, Tabanou, J., Wu, P., Clark, B., Mills, R. and Williams, R., 1996, Resisitivity while drilling - images from the string, Oilfield Rev., 8(1): 4-19. 
32. Shell U.K. Exploration and Production, 1996, Accelerating the application of new well technology, UEPS/21, July 1996 OTR.40942.

33. Ogden, P.H. (ed), 1994, Recent advances in oilfield chemistry, Proc. $5^{\text {th }}$ RSC Intnl. Symp. On Chemistry in the Oil Industry (Ambleside, UK, 13-15 April 1994).

34. SPE, Richardson, Texas, 1997, Drilling fluids, SPE Reprint Series, 44.

35. Fraser, L., Stanger, W., Griffin, T., Jabri, M., Sones, G., Steelman, M. and Valko, P., 1996, Seamless fluids programs: a key to better well construction, Oilfield Rev., 8(2): 42-56.

36. Carlson, J., Gurley, D., King, G., Price-Smith, C. and Waters, F., 1992, Sand control: why and how?, Oilfield Rev., 4(4): 41-53.

37. Bamforth, S., Besson, C., Stephenson, K., Whittaker, C., Brown, G., Catala, G., Rouault, G., Theron, B., Conort, G., Lenn, C. and Roscoe, B., 1996, Revitalising production logging, Oilfield Rev., 8(4): 44-64.

38. Brown, G., 1995, Using production logging data from horizontal wells, Trans. SPWLA $36^{\text {th }}$ Ann. Logging Symp. (Paris, 26-29 June 1995): paper SS.

39. Economides, M. and Nolte, K.G., 1989, Reservoir stimulation ( $2^{\text {nd }}$ edition) (Prentice Hall, Englewood Cliffs, NJ USA).

40. Fraser, L., Reid, P.I., Williamson, L.D. and Enriquez Jr., F.P., 1996, A study of the effect of drilling fluid fines on reservoir performance, J. Pet. Tech., 48(3): 234-236.

41. Baker, A., Gaskell, J., Jeffery, J., Thomas, A., Veneruso, T. and Unneland, T., 1995, Permanent monitoring - looking at lifetime reservoir dynamics, Oilfield Rev., 7(4): 32-46.

42. LeBlanc, L., 1995, Downhole separator uses hydrocyclone, zone discharge, Offshore, June 1995, 16.

43. Crowe, C., Masmonteil, J., Touboul, E. and Thomas, R., 1992, Trends in matrix acidizing, Oilfield Rev., 4(4): 24-40.

44. Sorbie, K.S., Yuan, M.D., Todd, A.C. and Wat, R.M.S., 1991, The modelling and design of scale inhibitor treatments in complex resevoirs, SPE Intl. Symp. On Oilfield Chemistry (Anaheim, 20-22 Feb.): SPE 21024.

45. Malandrino, A., Yuan, M.D., Sorbie, K.S. and Jordan, M.M., 1995, Mechanistic study and modelling of precipitation scale inhibitor squeeze processes, SPE Intl. Symp. On Oilfield Chem. (San Antonio, 14-17 Feb.): SPE 29001.

46. Borling, D., Chan, K., Hughes, T. and Sydansk, R., 1994, Pushing out the oil with conformance control, Oilfield Rev., 6(2): 44-58.

47. Bartosek, M., Mennella, A., Lockhart, T.P., Causin, E. and Rossi, E., 1994, Polymer gels for conformance treatments: propagation of $\mathrm{Cr}(\mathrm{III})$ crosslinking complexes in porous media, SPE/DOE $9^{\text {th }}$ Symp. On Improved Oil Recovery (Tulsa, 17-20 Apr.): SPE/DOE 27828.

48. Bond, A.J., Blount, C.G., Davies, S.N., Keese, R.F., Lai, Q.J. and Loveland, K.R., 1997, Novel approaches to profile modification in horizontal slotted liners at Prudhoe Bay, SPE Ann. Tech. Conf. (San Antonio, Texas, 5-8 Oct. 1997): SPE 38832,.

49. Salter, A. and Thakur, G., 1994, Integrated petroleum reservoir management - a team approach (PennWell Books, Tulsa, OK USA).

50. Arango, G., Colley, N., Connelly, C., Greenes, K., Pearse, K., Denis, J., Highnam, P., Durbec, C., Gutman, L., Sims, D., Jardine, S., Jervis, T., Smith, R. and Miles, R., What's in IT for us?, Oilfield Rev., 9(3): 2-19. 
